\title{
Oral HPV Infection: Current Strategies for Prevention and Therapy
}

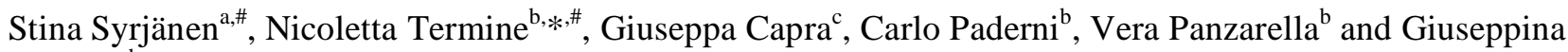 \\ Campisi ${ }^{\mathrm{b}}$
}

${ }^{a}$ Department of Oral Pathology, Institute of Dentistry, University of Turku, Turku, Finland; ${ }^{b}$ Sector of Oral Medicine “ V. Margiotta", Section of Oral Sciences, Department of Surgical and Oncological Disciplines, University of Palermo, Palermo, Italy; ${ }^{c}$ Section of Virology - Department of Sciences for Health Promotion, University of Palermo, Palermo, Italy

\begin{abstract}
Infection with High Risk (HR) Human Papillomaviruses (HPVs) is the main aetiological agent of Cervical Squamous Cell Carcinoma (CSCC) and also associated in a subgroup of other neoplasms, including Oropharyngeal Squamous cell Carcinoma (OPSCC). HPV infection, in genital as in oral mucosa, can also be subclinical or associated with benign proliferative lesions (common warts, condylomas, papillomas) caused mostly by infection with Low Risk (LR)-HPVs. In the last decades, extensive research has resulted in growing knowledge on HPV biology and specifically viral life cycle, biochemical properties of viral proteins and their interaction with the host proteins leading to potential new targets of prophylactic or therapeutic vaccines and therapies for HPV infection. In addition, notable progresses have been made in the field of diagnostics to detect HPV DNA or RNA. The recent epidemiological data suggest the significant changes in HPV endemic, due to the changes in sexual habits especially among young generations (i.e. early sexual debuts, multiple sexual partners, oral and anal sex); this scenario has urged on the need of adequate campaigns of primary (sexual education, vaccination programs) and secondary prevention (diagnostics of HPV-related diseases). Due to the growing interest on HPV infection and HPV related cancers, the authors made a narrative review of the literature on oral HPV infection and oral-genital transmission. After this, in view of the controversies about the strategies of therapy and prevention of HPV infection, the present review focuses on the current state of art about the available tools for the therapeutic and, if any, preventive management of oral HPV infection.
\end{abstract}

Keywords: Human papillomavirus, oral mucosa, oral diseases HPV-related, viral transmission, oral surgery, HPV vaccines, genital HPV infection, oral sex, head and neck cancer.

\section{INTRODUCTION}

Human Papillomavirus (HPV) infection has been recognized as a necessary cause of cervical squamous cell carcinoma (CSCC) worldwide [1-3]. There is also strong evidence of its causal role for a subset of SCC, in the anogenital area (i.e. vulva, vagina, anus and penis) and in the head-neck districts (i.e. pharynx, larynx, oral cavity). Genital HPV infection is one of the most frequent sexually transmitted disease, being reported with a prevalence of about $42 \%$ among 19-54 aged females in the US [4] and being strongly correlated to sexual behavioural risk factors [5]. Moreover, epidemiological data from last decades suggest significant changes in HPV endemic, with regard not only to genital but also oral area. This has been explained by risky sexual behaviour especially among young generations $[6,7]$. This also would explain the increased incidence of HPV-related SCC in head and neck region [8-10]. Although the modes of HPV transmission in oral cavity (see below, paragraph 2.a) are still not completely elucidated, epidemiological data suggest that detection of HPV (i.e. HPV 16) in oral exfoliated cells increased the risk more than 14-fold (OR 14.6; 95\% CI: 6.3-36.6) of oropharyngeal cancer (tonsils and base of tongue) [11] and 3.8fold the risk of oral cancer [12].

HPV-related diseases in humans have taken an increased importance over the years and are now a major concern for public health. The current evidence suggests that the potential fallouts of the so called "HPV endemic" on the epidemiologic, therapeutic/preventive and socio-economic viewpoints are enormous, and in the future there is a great opportunity to design adequate strategies of prevention and management of HPV-related diseases, including SCCs of anogenital and head-neck region, similarly to other infectious

*Address correspondence to this author at the Sector of Oral Medicine "V. Margiotta", Section of Oral Sciences, Department of Surgical and Oncological Disciplines, University of Palermo, Palermo, Italy;

Tel:/Fax: +39091 6552236; E-mail: ntermine@odonto.unipa.it

${ }^{\#}$ S. Syrjänen S. and N. Termine contributed equally to the manuscript preparation. diseases, although the medical and especially dental community, is probably still not acquainted with these perspectives.

This review focuses on oral HPV infection and oral-genital transmission and current state of art about the therapeutic and, if any, preventive management of oral HPV infection.

\section{VIROLOGY AND NATURAL HISTORY OF HPV INFEC- TION}

\subsection{HPV Genome and Source of Infection}

HPV are small, double-stranded DNA viruses with around 8000 base pairs, covered by an iso-exahedric capsid without envelope consisting of 72 capsomeres [13-15]. Capsid proteins are represented by a major capsid protein (L1) and a minor capsid protein (L2). HPV genome consists of ten Open Reading Frames (ORFs) sequences, with potential of transcription for specific mRNA found in the same DNA strand. The HPV genome can be divided into three different regions: the first region (Early or "E" region) extends for about $45 \%$ of the viral genome and codifies for 8 earlyfunctional proteins (E1 - E8); the second one (Late or "L" region) extends for about $40 \%$ of the viral DNA and codifies for 2 latestructural proteins (L1 and L2); the third one (Long Control Region or "LCR" or Upstream Regulatory Region "URR"), containing sequences regulating gene transcription, performs exclusively regulatory functions [16-18]. After HPV inoculation, the life cycle of HPV, the synthesis of viral DNA and the expression of viral genes are linked to the differentiation program of the infected epithelial host cells, with production of mature virion particles restricted to differentiated superficial cells [19]. The normal viral replication cycle is a highly regulated process. Thus, the dynamic of changes in keratinocytes, from the basal layer up to the surface, predisposes to the creation of a suitable micro-environment for the productive cell replication, responsible for the transformation of the epithelial cell into a permissive cell $[19,20]$.

Infection usually occurs through micro-wounds of the epithelium that expose basal and para-basal cells of the squamous epithelium to viral access. This process it seems coordinated by specific 
HPV receptors, including $\alpha-6$ integrin, extracellular laminin 5 and heparan sulphate proteoglycans. After entry, HPV establishes itself in the cellular nucleus as episomes with a low, non-productive viral replication (vegetative replication) [18]. In the basal cells HPV replicates together with cellular DNA during S-phase at relative low copy numbers (20-100 copies). This initial phase, responsible for the latent status of infection is characterized by ORFs E1 and E2 expression only, codifying for replication factors. In intermediate layer during differentiation the vegetative replication occurs and more than 1000 copies/cell are amplified in each cell. The episomal form is a kind of reservoir of infected cells, morphologically undistinguishable from non-infected ones; the classic viral cytopathic effects (acanthosis, diskeratosis, multinucleation of keratinocytes and coilocytosis) appear when the viral replication enters into a productive phase. It is characterized by the complete viral DNA codification and the assemblage of several infecting virions. Particularly, following the epithelial squamous differentiation, starting from basal and para-basal cells, where early portions of the viral genome are more active and going up to higher epithelial layers (both the intermediate and the superficial) along with the formation of the complete virions (i.e. the infecting viral particles) [19]. The virus is expelled from the epithelial cells when they undergo desquamation and is transmitted by direct contact (especially in presence of lesions, i.e. genital warts) or by indirect contact.

The genital HPV infection is classified as a Sexually Transmitted Disease (STD): the transmission of the virus in the genital area is mostly due to sexual contact with an infected partner and the probability of infection is directly related with a sexual risk behaviour (e.g. early sexual debut, high number of partners) [21, 22]. Conversely, the transmission modes of oral HPV infection, the risk factors as well as the natural history is poorly studied. Sexual transmission is by far the most common route of spreading the virus. However, detection of HPV in virgins, infants and children suggest that vertical transmission also exists, but the exact rates and routes have not been well established [23-29]. Possible non-sexual transmission modes include vertical or horizontal transmission and auto-inoculation. Vertical transmission can be divided into three categories, according to the assumed time of HPV transmission: 1) peri-conceptual transmission (time around fertilization), 2) pre-natal (during pregnancy), and 3) peri-natal (during birth and immediately thereafter). Controversial views have been presented on oral sex as a main transmission mode of HPV [24, 30]. In the more recent Finnish Family HPV Study on HPV dynamics within family, $11 \%$ and $26 \%$ of the women and their husbands reported regular practice of oral sex, respectively [24, 25]. However, any significant association between oral sex and carriage of HPV in the oral mucosa was established [25]. This is contradictory to the data reported by D'Souza and co-workers, who studied in a case-control setting, whether sexual behaviour that increased the odds of oropharyngeal cancer would similarly increase the risk of oral HPV infections among their control patients [30]. HPV infection was detected in $4.8 \%$ of 332 control patients (from an outpatient clinic) and in $2.9 \%$ of 210 college-aged men. Among control patients, the odds of HPVinfection developing independently increased with increased lifetime number of oral $(\mathrm{P}=0.007)$ or vaginal sex partners $(\mathrm{P}=0.003)$. Among college-aged men, there was an association between oral HPV and deep kisses $(\mathrm{P}=0.023$, for trend) and oral sex $(\mathrm{P}=0.046$, for trend) [24]. The importance of sexual transmission is confused by the fact that the HPV-type concordance in oral and genital infections seems to be poor between the sexual couples and even in the same person [26, 31-33].

\subsection{Natural History of HPV Infection}

The current knowledge about the natural history of oral HPV infection come from gynaecological literature about cervical infection, although, as recently suggested by D'Souza et al [34], oral and genital HPV infection seem to differ themselves about some aspects.
Regarding the natural history of cervical HPV infection, it would depend on the genotype involved. HPVs are traditionally distinguished, on the base of specific epithelial tropism, in cutaneous and mucosal types: the firsts infect hands and feet skin, the second prefer mucosal surface of upper aero-digestive tract, anogenital district, urethra and conjunctive [35-38]. On the basis of epidemiologic data regarding the behaviour of the viral lesions, HPV have been also divided in two groups: those at "high risk" oncogenic [High Risk (HR) -HPV genotypes like 16-18-31-33-35, $39,45,51,52,53,56,58,59,66,67,70,73,68,82)$, associated with potentially and overtly malignant lesions (anogenital cancers, giant condyloma of Bruschke and Lowenstein) and those at "low risk" oncogenic [Low Risk (LR)-HPV genotypes like 2, 4, 27 (the skin types) and mucosal types $6,11,13,32,42)$, more commonly associated with benign diseases (ordinary wart, condyloma, focal epithelial hyperplasia, squamous cells papilloma, Bowen's papillomatosis) [39-43]. After entry to host cell, HPV infection can manifest in two clinical states:

1) subclinical or unapparent infection, that is the silent presence of viral genome into inoculation site without any clinical and/or histological and/or cytological alterations of cervical mucosa [44];

2) clinical infection, expression of proliferation of infected keratinocytes and associated with clinical and histological lesions of cervical mucosa. These lesions are usually benignant (e.g. genital condylomas or warts) when infection is sustained by LR HPV [45]; conversely the HR HPV infection, especially when it persists for over 18-24 months [46] and it is accompanied by the viral DNA integration into the eucariotic DNA in basal cells, may be associated with the development of potentially malignant and malignant epithelial lesions of the cervical mucosa. The latter form of infection has been recognized as the necessary but not sufficient cause of cervical SCC [46, 47].

This biological and aetio-pathogenetical model related to cervical HPV infection has been shifted to oral infection, although with some important differences derived from very recent researches, discussed below.

Immune response plays a very important role in HPV infection; it is well documented, for instance, that in immunocompetent subjects skin warts often regress spontaneously, whereas immune deficiency, both inherited (e.g. warts-like epidermal dysplasia) and acquired (e.g. transplants, AIDS), may favour a higher incidence and persistence of skin and mucosal infections induced by HPV [48]. Nevertheless, in HPV-related diseases, immune responses are generally poorly expressed compared to other viral infections, since the viral replication cycle takes place inside maturing keratinocytes able to continuously remove mature virions. These viruses also cause cell proliferation, rather than cell lysis; as a result, during infection, the local or systemic viral antigens presentation to the immune system by the APC is minimal and infection generally persists for months or even years [49].

\section{CLINIC OF HPV INFECTION}

\subsection{Genital HPV Infection}

It is believed that genital HPV infection could result in two different conditions, depending largely on the genotypes involved (Table 1).

\section{Genital Normal Mucosa and HPV Infection}

HPV detection in healthy genital mucosa is a common condition characterized by staying silent of the viral genoma in the site of inoculation and, therefore, without any clinical, colposcopic, cytological and histological resultants. The infection can be discovered only with the detection of HPV-DNA in the epithelial cells, by means of techniques of hybridization on cytological or histological samples taken from healthy subjects. 
Table1. Conditions Potentially Associated with HPV Infection in Genital/Cervical Mucosa

TAB.1 CERVICAL/GENITAL HPV INFECTION

\begin{tabular}{|c|c|c|}
\hline SUB-CLINICAL & \multicolumn{2}{|c|}{ CLINICAL } \\
\hline \multirow{2}{*}{ Normal mucosa } & BENIGN LESIONS & $\begin{array}{c}\text { POTENTIALLY/OVERTLY MALIGNANT } \\
\text { DISORDERS }\end{array}$ \\
\hline & $\begin{array}{l}\text { Condyloma acuminatus } \\
\text { Warts (Verruca vulgaris) }\end{array}$ & $\begin{array}{c}\text { CIN, VaIN, VuIN, AIN, PIN } \\
\text { SCC of uterine cervix, vagina, vulva, anus, penis }\end{array}$ \\
\hline
\end{tabular}

CIN: Cervical Intraepithelial Neoplasia; VaIN: Vaginal Intraepithelial Neoplasia; VuIN: Vulvar Intraepithelial Neoplasia; AIN: Anal Intraepithelial Neoplasia; PIN: Penis Intraepithelial Neoplasia.

Subclinical infection can be further distinguished in productive, when it is accompanied by the expression of viral DNA and by the release of mature viral particles, and latent/persistent, when the virus persists, for a variable time, as episome, in the deep layers epithelium in a completely silent condition. Persistent HPV infection supported by HR is seen as a necessary, but not sufficient, state for the occurrence of cervical cancer [46]. It is estimated that a wide range of healthy and sexually active female population is a carrier of subclinical genital infection, contributing to the spread of the virus. The prevalence of infection among worldwide population of healthy women was estimated to be between $2 \%$ and $44 \%$ in relation to the sensitivity of the diagnostic test applied [44, 47, 50-52]. The highest prevalence (about $40 \%$ ) of HPV infection was found among women under the age of 25 years, progressively reduced in successive age groups [53]. These data support the hypothesis that the virus, acquired after the onset of sexual activity, leading to transient infection, is eliminated in about 6-20 months [53, 54]. This time of clearance seem to be longer only for HPV-16 infection [18, $22,55,56]$. The genotypes isolated more frequently, both in patients with cervical carcinoma and in healthy controls, are 16, 18, 45, 31 and 58; it is also common the detection of infection with multiple genotypes, with percentages prevalence in the two groups of $8,1 \%$ and $13.9 \%$ respectively [55].

In a very recent investigation on HPV infection in U.S. female, Hariri and colleagues, show a prevalence estimate for HPV equal to $42.5 \%$ [4]. This percentage drops dramatically $(8.8 \%)$ if the genotypes considered are only those at high risk (HR 16 and 18), with higher prevalence among women aged 20-24 years [5].

However, as renowned by Sanders et colleagues, most of these cross-sectional estimates of HPV prevalence fail to connect the HPV status with a chronic infection and its role in malignant transformation of healthy mucosa. A longitudinal design is needed for all future research aimed to investigate the causal link between HPV infection and its oncogenic potential [6].

\section{Genital Benign Lesions HPV-related}

The most frequent clinical expression of infection is the condyloma acuminatum, macroscopically characterized by small, sessile or pedunculated multiple growths, generally asymptomatic, covered with keratinized epithelium, tending to confluence and to growth like a "cauliflower". It is the most common sexual transmitted viral infection (although it can also be acquired by vertical transmission or extragenital contact) associated in $95 \%$ of cases with infection by LR-HPV 6 and 11 [22, 45, 57]. The lesion, expression of a benign polyclonal proliferation of infected keratinocytes, may regress spontaneously in 3-4 months, may remain stable or undergo an expansion.

Genital warts represent another common disease related to the productive infection of HPV, especially that supported by LR-HPV 6 or 11. Diagnosis of genital warts can be confirmed by biopsy, although biopsy is needed only under certain circumstances (e.g., if the diagnosis is uncertain; the lesions do not respond to standard therapy; the disease worsens during therapy; the patient is immunecompromised; or warts are pigmented, indurated, fixed, and ulcerated). No data support the use of type-specific HPV nucleic acid tests in the routine diagnosis or management of visible genital warts.

In addition to the external genitalia (i.e., the penis, vulva, scrotum, perineum, and perianal skin), genital warts can occur on the uterine cervix and in the vagina, urethra, anus, and mouth; these warts are sometimes symptomatic. Depending on the size and anatomic location, genital warts can be painful, friable, and pruritic, although they are commonly asymptomatic.

HPV types 16, 18, 31, 33, and 35 are found occasionally in visible genital warts and have been associated with external genital (i.e., vulvar, penile, and anal). Patients who have visible genital warts can be infected simultaneously with multiple HPV types [5, 58].

\section{Genital Potentially/Overtly Malignant Lesions HPV-related}

HPV persistent infection, supported by HR genotypes, is considered a necessary condition and an important cause for the occurrence of cervical and anogenital (such as vaginal, vulvar, penile and anal) potentially/overtly malignant lesions respectively [59]. Due to the close connection between HPV infection and cervical cancer, the discussion will focus on that district.

Cervical potentially malignant lesions are defined as circumscribed areas of the mucosal lining of the cervix characterized by varying degrees of epithelial dysplasia, burdened by a greater neoplastic potential than the normal mucosa. Over $90 \%$ of these conditions are HPV-positive; in some cases, the genome is only present in episomic or integrated form, in other cases, the complete virions are visible by electronic microscope [45, 60-64].

From histological point of view, dysplastic lesions usually have an uneven surface, sharp edges, non-uniform caliber of vessels, after application of acetic acid often assume pearly white bulleted or "mosaic" and are iodine-negative at test of Schiller.

According to the Bethesda classification, there are three categories of cytological findings concerning these cervical lesions:

I. ASC (Atypical Squamous Cells), further divided into:

I.a ASC-US (Atypical Squamous Cells of Undetermined Significance);

I.b ASC-H (Atypical Squamous Cells, cannot exclude HSIL);

II. L-SIL (Low-grade Squamous Intraepithelial Lesion);

III. H-SIL (High-grade Squamous Intraepithelial Lesion);

IV. Carcinoma.

Currently, researchers are apt to believe that the lesions referred to as L-SIL and H-SIL are the expression of two distinct pathogenetic processes, both induced by HPV. The genotypes more detected are the HR, except for a portion of L-SIL, about $30 \%$, resulting LR-HPV- positive $[22,60]$. The L-SILs represent the transient 
expression of viral production, and are not accompanied by disruption of differentiation and maturation processes of epithelium. The H-SILs, however, are considered the true precursors of cervical cancer. These lesions are the result of HPV infection in metaplastic and immature cells, resulting in disruption of the differentiation process of epithelium, in the uncontrolled replication of cells and in the accumulation of genetic abnormalities, to the selection of a clone of cancer cells [22]. The mean age of H-SIL onset is 28 years; compared with the average ages of acquisition of HPV infection (20-25 years) and of onset of cervical cancer (40-50 years), we deduce some key points: the interval of time during which the virus is able to induce dysplastic changes is relatively short, while the time needed within these alterations develop invasive cancer is about two decades.

This suggests a very long time to tumor progression, during which a variety of factors, in addition to HPV, play a role in promoting the malignant progression.

Cervical carcinoma represents the second cause of death among women worldwide after breast cancer. The curve of incidence of this tumor shows a gradual increase to over 55 years, with a peak around 48 years $[1,22,37,65,66]$. The association between genital HPV infection and cervical cancer, suggested in the 80 s by Harold zur Hausen [67] has been widely confirmed by numerous epidemiological and molecular studies carried out in the last decades. The DNA of HPV 16, 18 and 33 has been shown in over $90 \%$ of invasive cervical carcinomas [1,68-71]. The information obtained in the last years on the replication cycle of the virus and its interaction with the transitional epithelium of the cervix, have allowed the development of a pathogenetic model of cervical cancer consists of three basic stages:

i) persistent HR HPV;

ii) progression of HVP-related epithelial dysplasia (from mild to severe degree);

iii) local tumor invasion and distant spread.

The reason why a small percentage of infections tends to persistence and neoplastic evolution is still debated and, according to the most recent and accredited acquisitions, is to search in the interindividual differences in HLA (Human Histhocompatibilty Leukocyte Antigen) haplotype [46].

\subsection{Oral HPV Infection}

The natural history of viral infection in the oral cavity is not clear, though having characteristics in common with those described for the cervical district. In the oral cavity, HPVs have been detected both in healthy oral mucosa and in several lesions, as reported on Table 2.

\section{Normal Oral Mucosa and HPV Infection}

The detection rate of asymptomatic oral HPV infection in adults (i.e. presence of HPV DNA) varies among different studies from $0 \%$ to $81 \%$. The mean prevalence rate is approximately $11 \%[6,7$, 72-81]. Kreimer and co-workers made a new meta-analysis on HPV detection in oral mucosa and showed that only $4.5 \%$ (95\% CI: $3.9-$ $5.1)$ of 4070 subjects were positive for any HPV and 3.5\% $(95 \%$ CI: 3.0-4.1) of 4441 subjects had carcinogenic mucosal HPV [59]. HPV16 was detected in $1.3 \%$ (95\% CI: $1.0-1.7 \%$ ) of 3977 healthy subjects accounting $28 \%$ of all HPV positive cases of the oral region [82]. Detection rate of any HPV varied widely in individual studies from $2.6 \%$ to $20.7 \%$, even when the same PCR primers were used [59]. The reasons for this variability would be found in the lack of standardization of the parameters used in the several investigations such as: samples size characteristics of ethnogeographic and socio-demographic variables of the populations examined, the nature of the specimens (histology vs. cytology), sensitivity of the diagnostic test used for the viral detection (ie, $\mathrm{SBH}, \mathrm{DBH}, \mathrm{ISH}, \mathrm{PCR}$ and nested variant) and inclusion criteria for mucosal lesions based on different classification systems [59, 79]. The most recent systematic review of the literature on this topic selected 18 studies investigating HVP-DNA prevalence in 4581 cancer-free subjects which resulted in a $4.5 \%$ and $3.5 \%$ overall prevalence of any HPV and HR-HPV only, respectively [82]. These results are similar to those reported in a previous systematic review regarding HPV infection in OSCC and potentially malignant disorders [12] that registered, among control samples from healthy oral mucosa, percentages of HPV infection equal to $12 \%$. Based on these results, it is believed that the oral mucosa represents a reservoir of infection, excluding a primary involvement of the virus in the process of oral carcinogenesis.

\section{Oral Benign Lesions HPV-related}

HPV has involved in a variety of benign oral lesion such as common wart (verruca) (Fig. $\mathbf{1}$ and 2), condyloma acuminatum (Fig. 3), squamous cell papilloma (SCP) (Fig. 4 and 5) and focal epithelial hyperplasia (FEH) (Fig. 6). These are asymptomatic exophytic growths, single or multiple, with surface smooth or warty, white or pinkish depending on the degree of epithelial keratinization; from the histological point of view are characterized by epithelial polyclonal proliferation, koilocytosis and dyskeratosis [83-85]. The lesion may affect any part of the oral surface, more frequently on the tongue, the soft palate and the lips. These lesions

Table 2. Conditions Potentially Associated with HPV Infection in Oral Cavity

TAB. 2 ORAL/OROPHARYNGEAL HPV INFECTION

\begin{tabular}{|l|l|l|}
\hline \multicolumn{2}{|c|}{ SUB-CLINICAL } & \multicolumn{2}{|c|}{ CLINICAL } \\
\hline \hline \multirow{2}{*}{ Normal mucosa } & BENIGN LESIONS & $\begin{array}{l}\text { POTENTIALLY/OVERTLY } \\
\text { DISORDES }\end{array}$ \\
\cline { 2 - 4 } & Squamous cell papilloma & $\begin{array}{l}\text { Oral potentially malignant disorders (OL, PVL, } \\
\text { OLP) }\end{array}$ \\
& Condyloma acuminatum & OSCC, VC, OPSCC \\
& Wart (verruca vulgaris) & Focal epithelia hyperplasia \\
\hline
\end{tabular}

OL: Oral Leukoplakia;PVL: Proliferative Verrucous Leukoplakia; OLP: Oral Lichen Planus; OSCC: Oral Squamous Cell Carcinoma, VC: Verrucous Carcinoma, OPSCC: Oropharyngeal Squamous Cell Carcinoma 


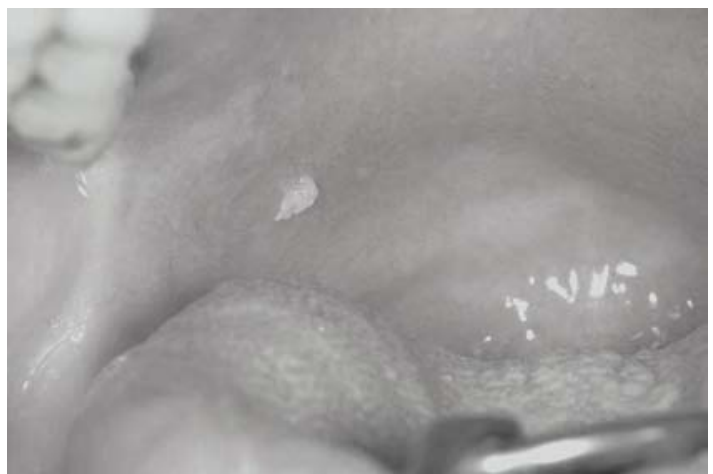

Fig. (1). Oral wart of the hard palate.

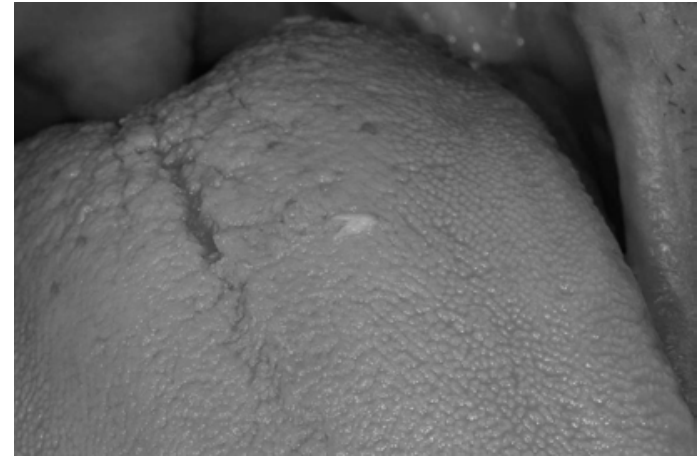

Fig. (2). Oral wart of the dorsal surface of the tongue.

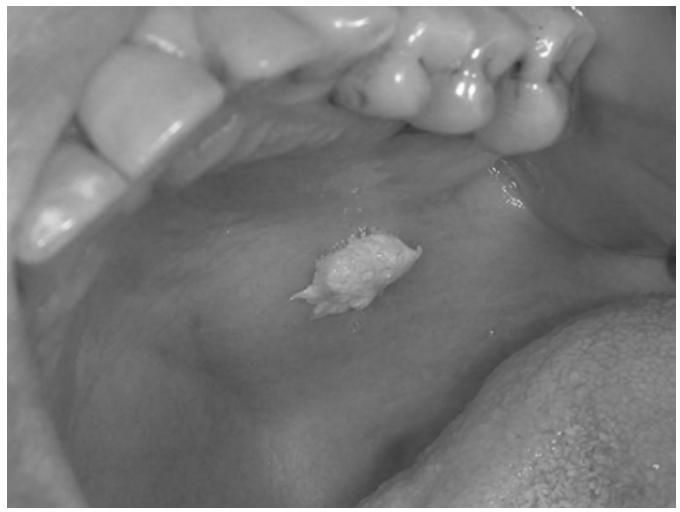

Fig. (3). Condyloma acuminate of the palate.

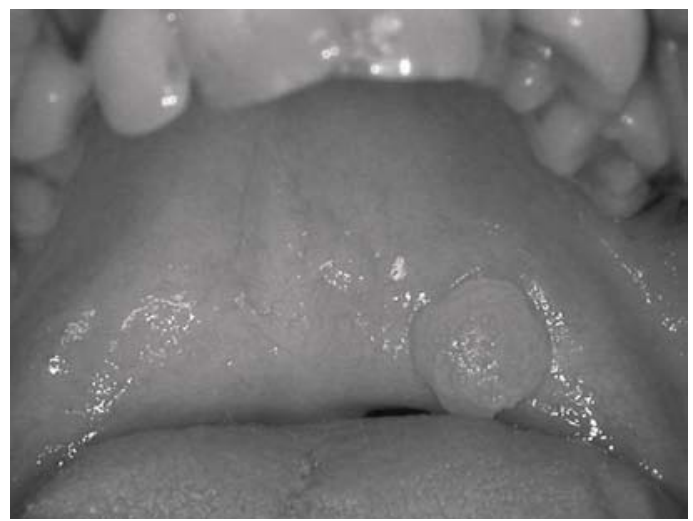

Fig. (4). Oral squamous cell papilloma (SCP) of the palate.

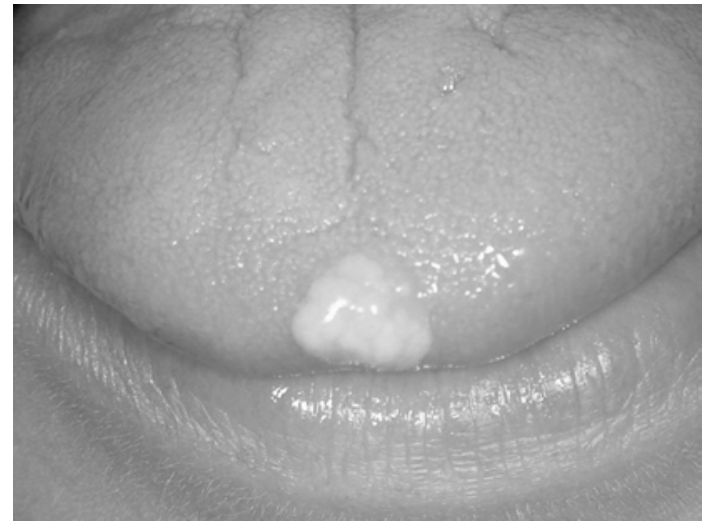

Fig. (5). Oral SCP of the tongue.

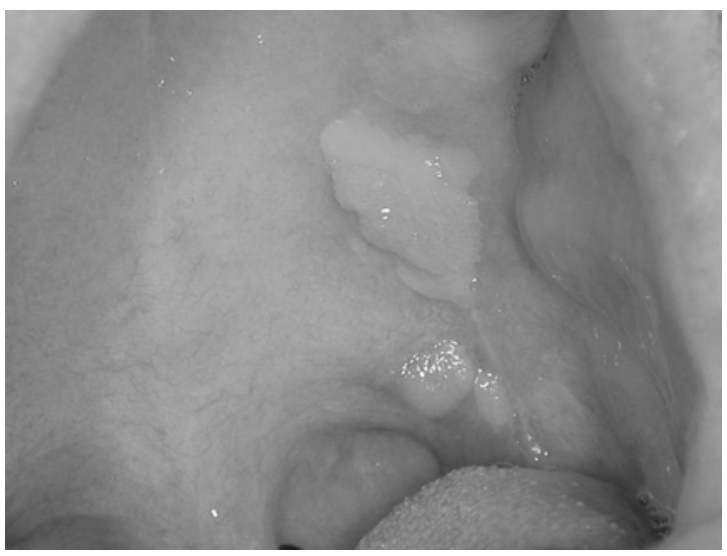

Fig. (6). Focal Epithelial Hyperplasia (FEH) of the hard and soft palate.

are in most cases clinically indistinguishable and their differential diagnosis is based on histopathology. Condyloma acuminatum is characterized by a central core connective tissue in a treelike structure covered with epithelium presenting acanthosis (ie hyperplasia of the spinous layer), koilocytosis (ie presence of cells with pyknotic and irregularly shaped nuclei surrounded by a perinuclear vacuolation), parakeratosis (i.e. abnormal formation of horn cells of the not keratinized epithelium caused by the persistence of nuclei, incomplete formation of keratin, and moistness and swelling of the horn cells) associated with the presence of chronic inflammatory infiltrate in the dermis. Oral SCPs are a small benign growth that begins in squamous epithelial cells. The lesion appears as a soft, pedunculated mass with numerous finger-like projections. The projections may be long and pointy or short and rounded if keratin (skin-forming protein) has built-up round the lesion. Less keratinized lesions are pink or red in color and resemble a raspberry, whilst heavily keratinized lesions are white and look like the head of a cauliflower. The covering squamous epithelium shows a normal maturation pattern, although occasional papillomas demonstrate pronounced basilar hyperplasia and mild mitotic activity which could be mistaken for mild epithelial dysplasia may or may not be found in the superficial layers of the epithelium. The SCP differs from the oral condyloma acuminatum in that its surface projections are typically more elongated and more often pointed. It will usually have considerably more keratin on its surface and is much less likely to contain koilocytes in large numbers. The verruca vulgaris is also characterized by a proliferation of hyperkeratotic stratified squamous epithelium arranged into finger-like or pointed projections, each with its connective tissue core. It differs from SCP in that elongated rete ridges tend to converge toward the center of the lesion, producing a "cupping" effect. Also, a prominent granular cell layer (hypergranulosis) exhibiting coarse, 
clumped keratohyaline granules is typically found and abundant koilocytes are often seen in the superficial spinous layer. Eosinophilic intranuclear viral inclusions are sometimes noted within the cells of the granular layer, a feature never found in the SCP. The HPV-related etiology of these lesions is suggested by the presence of LR HPV DNA, such as HPV -2, HPV-4 and HPV-57 (warts), HPV-6 and HPV-11 (SCPs and condylomas), HPV-32 and HPV-13 (FEH), in more than $80 \%$ of cases [28].

There are no population-based studies on the incidence or prevalence of oral papillomas or condylomas. The largest cohort comprises 20.000 Swedish citizens, of whom $0.1 \%$ had oral warty lesions [86].

SCPs are the most common benign tumors of oral epithelium. However, in some text books, papillomas are clumped together with benign epithelial neoplasia, which represent a reaction to injury rather than true tumors. SCPs are reported to be most frequent in children and adults in their 4th and 5th decades. There are also some rare syndromes which are known to be associated with multiple oral papillomas, e.g. focal dermal hypoplasia syndrome, acrodermatitis enteropatica, Cowdens's syndrome, nevus unius lateralis, Costello syndrome and Down syndromes (OMIM data base, http: //www.ncbi.nlm.nih.gov/omim OMIM).

Oral condylomas have been traditionally associated with oral sex, in contrast to oral SCP. However, no reliable differential diagnostics can be done between oral SCP and oral condyloma on the basis of this socio-behavioural variable. In the literature published by 1998 , the author found a total of 481 SCPs and 284 OCs, of which $50 \%$ and $75 \%$ tested HPV-positive. HPV6 and 11 were the major HPV types in these lesions [43, 81, 87-90].

The role of HPV in other benign epithelial hyperplasia is unknown. Recently some evidence was presented that the majority of white oral patches' containing hyperplasia but not dysplasia harbor low copies of HR HPV DNA [91].

\section{Oral Potentially Malignant/Overtly Disorders HPV-related}

HPV prevalence, in oral potentially malignant disorders (OPMD) and in oral squamous cell carcinoma (OSCC) ranges from $0 \%$ to $85 \%$ [43] with a higher prevalence of HPV 16 or 18 genotypes [92-96]. Such a wide variation is probably due to: i) demographic variables, ii) different categorization of lesions investigated (sometimes not supported by histology) and different site of the mucosa examined, iii) different sampling techniques (biopsies, mouth rinsing or brushing) and different detection techniques from the less sensitive ISH to the highly sensitive "nested" PCR [43].

To date, data on HPV prevalence in Oral Leukoplakia (OL) (Fig. 7) are still controversial. Miller and White [77], in a review of studies using ISH to identify HPV in benign OL (i.e. without dysplasia), reported a prevalence ranging from $0 \%$ to $80 \%$, significantly greater in fresh and frozen specimens $(43.1 \%)$ than in paraffin-embedded tissues (12.2\%). However, in OL with dysplasia and using PCR for HPV-DNA detection, the prevalence ranged from $17 \%$ [97] up to $68.6 \%$ [72]. Moreover, if Uppsala criteria are considered [98] and the Proliferative Verrucous Leucoplakia (PVL) is excluded from the analysis, the overall HPV prevalence in other OL dropped to $17.6 \%$ (in paraffin-embedded biopsies from nondysplastic and dysplastic lesions) [99].

Campisi et al examined the relationship in OL between HPV and some molecular predictors of malignant progression such as apoptosis markers (bcl-2 and survivin) and proliferation markers (Proliferating Cell Nuclear Antigen; PCNA). The risk of HR-HPV infection was found to be independently associated with survivin and PCNA expression, suggesting that these markers could be involved in HPV-mediated disorders of epithelial maturation [100].

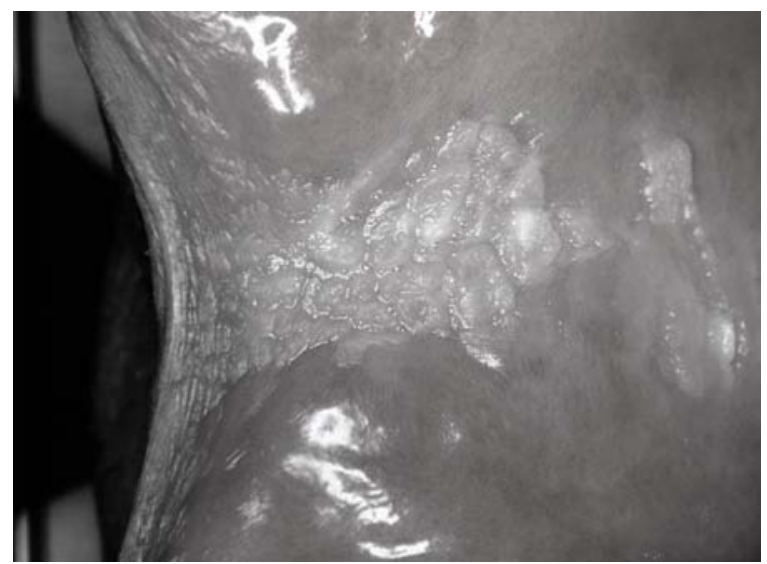

Fig. (7). Oral Leukoplakia (OL) - non homogeneous form - of the buccal mucosa.

Recently, Szarka et al reported an increase of HPV prevalence in OPMD with increasing malignant potential: $32.8 \%, 40.9 \%$ and $47.7 \%$ in Oral Lichen Planus, OL and OSCC respectively [101].

Oral proliferative verrucous leukoplakia (OPVL) (Fig. 8) is a different and particularly aggressive form of OL that, in the past, seemed to have the strongest relationship to HPV infection. After, the association of OPVL and HPV (especially genotype 16) has been supported by several reports [96, 102, 103], although with a wide range from $10 \%$ to $85 \%$, of HPV infection [96, 102]. However, a multi-centre study recently reported no statistically significant difference, in terms of HPV-DNA detection, between OPVL $(24.1 \%)$ and common OL $(25.5 \%)$ - nor any special role for HPV in PVL onset [104]. To date, this controversy remains not to be resolved.

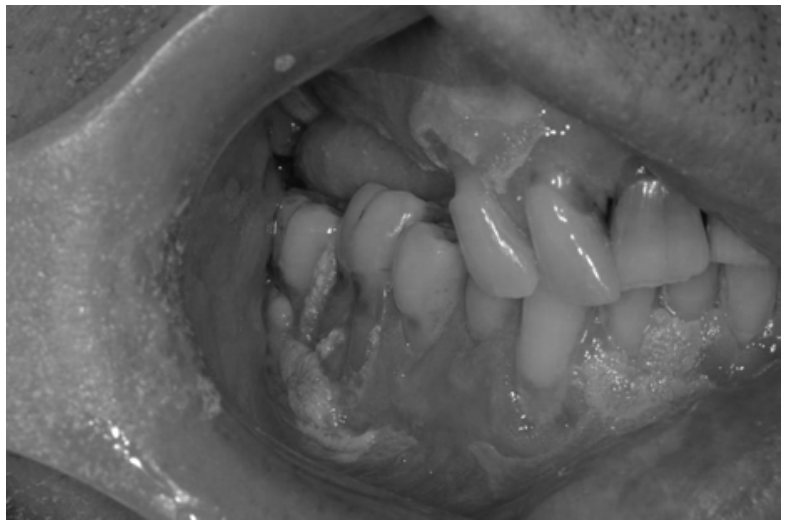

Fig. (8). Oral Proliferative Verrucous Leukoplakia (PVL) of the buccal and masticatory mucosa.

Oral erythroplakia (OE) (Fig. 9) is a potentially malignant disorder with the highest potential for malignant transformation. It is described as a "red patch clinically and pathologically un-related to any other disease" [105]. By 1998, only 11 OEs have been screened for HPV DNA and 54.5\% has tested HPV 16 positive [12].

Oral Lichen Planus (OLP) (Fig. 10) is a chronic inflammatory disease of unknown aetiology and immune pathogenesis, with a small malignant potential. Information on HPV infection in OLP is scanty, but the few studies published report a high frequency [106, 107] from $27.3 \%$ (75), to $42.0 \%$ [108] or even $65.0 \%$ [109]. Both Gonzales-Moles [110] and Jontell [109] observed that only the 


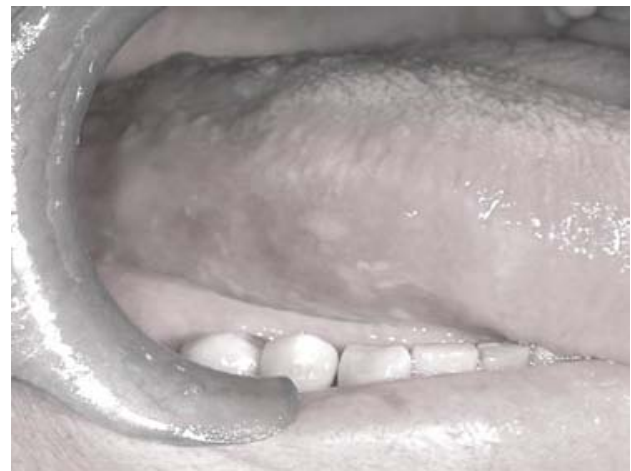

Fig. (9). Oral eritroplakia of the border of the tongue.

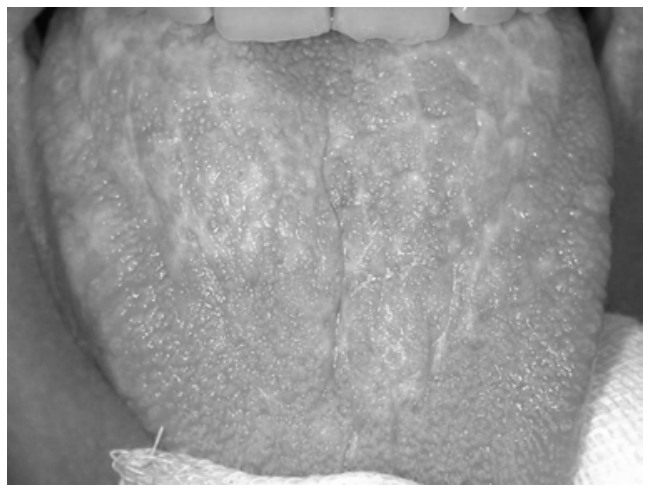

Fig. (10). Oral Lichen Planus - reticular form- of the tongue.

erosive variant of OLP was found to be HPV positive but this was not confirmed in another study [111]. In the recent systematic review of HPV and OPMDs, the prevalence of any HPV genotypes and only HPV-16 in OLP were 5.12\% and 5.61 respectively [12].

With almost 130,000 annual deaths worldwide, OSCC (Fig. 11 and 12) is considered a public health emergency [112]. Usually OSCC is characterized by a very aggressive behaviour and a poor prognosis, with an overall 5 years survival rate of $59.4 \%$, $[9,113]$. Recently, HR HPV genotypes have been identified as etiologic agents for a subset of SCCs of oral cavity and oropharynx, especially in non-smoker and non-drinker subjects $[114,115]$. The hypothesis of the participation of HPV in oral and oropharyngeal carcinogenesis was first proposed by Syrjanen et al [116] and then supported by several other authors $[38,65,117-121]$ on the basis of the following evidence: a) the epitheliotropic nature of HPV; b) the widely confirmed oncogenic potential of HR gt in the pathogenesis of anogenital neoplasms; and c) the morphological similarities between oropharyngeal and genital epithelia [122].

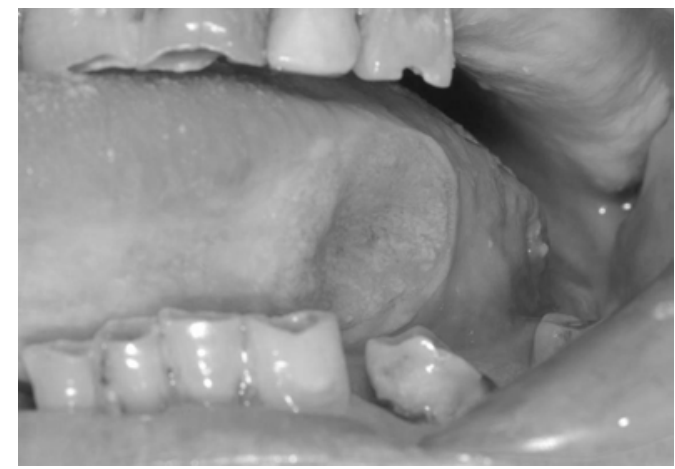

Fig. (11). Oral Squamous Cell Carcinoma (OSCC) of the tongue.

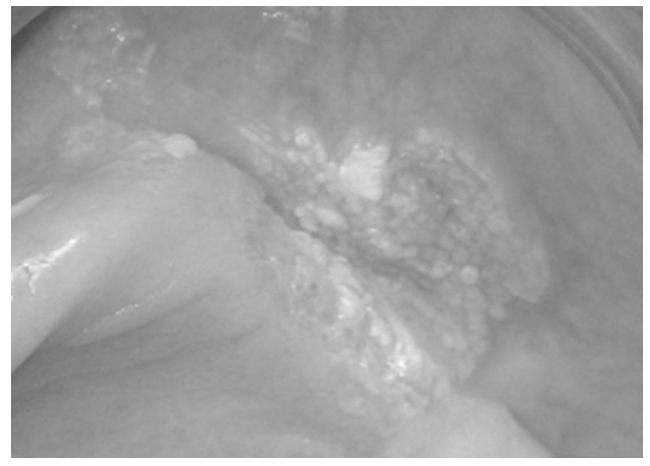

Fig. (12). OSCC of the alveolar ridge.

Nevertheless, the role of HPV infection in oral carcinogenesis is still unclear because conflicting results have been reported. A very wide range of viral prevalence $(0 \%-100 \%)$, in addition to the presence of HR HPV in normal oral mucosa, has been reported in literature [43, 73, 77]. Apart from the differences among the patient groups examined regarding ethno-geographical characteristics and sexual behaviour, this wide range of prevalence could be related to: i) the site of lesion (oral cavity vs. oropharynx and tonsils), and ii) the sensitivity of the applied diagnostic technique, in terms of sampling method and HPV detection procedure.

The last comprehensive meta-analysis conducted on this issue (and utilizing a strict case-control setting) showed that HPV significantly increase the risk for OSCC, as compared with the controls (OR 3.98, 95\% CI: 2.62-6.02); especially when HPV 16 is investigated (pooled OR 3.86, 95\% CI: 2.16-6.87) [12]. However, the HPV association was found to be significant also when biopsy samples of OSCC were compared with cytological samples of the controls. According to this findings and considering that that HPV infection is multi-focal (but not necessarily persistent/oncogenic), the authors recommend the use of biopsied tissue for HPV testing in future studies [12].

\subsection{Oro-genital HPV Infection}

Few published investigations have evaluated how frequently HPV infection occurs simultaneously in the oral districts and in the female genital area. Research so far has tried to clarify the nature of this correlation by studying social-behavioural risk factors and in particular, transference of the virus to different epithelial sites in the same patient. With regard to this aspect, various authors consider the two most common transmission patterns of HPV from one anatomic site to another, as being sexual transmission through oralgenital contact with an infected partner and self-inoculation. In order to study how infection is transmitted, various researchers have used questionnaires designed to assess the impact of factors likely to cause genital infection, such as, early sexual exposure, a high number of partners in general and in the last year, number of pregnancies, level of education, contraceptive methods, sexual habits and also personal hygiene standards of the patients. On examining studies, the main topic to be considered is the direct association between the sensitivity of the diagnostic test used and the percentage of oral-cervical infection detected. Kellokoski et al, in a study carried out over ten years ago on women with current and previous genital HPV infection, detected an elevated percentage of the virus present in normal oral mucosa in relation to the diagnostic protocol adopted: respectively through Dot Blot Hybridization (DBH) on cytologic samples the prevalence was $3.3 \%$, by means of Southern Blot Hybridization (SBH) on histologic samples, prevalence was $15.6 \%$ and lastly by means of PCR, on the same samples, there was $23.1 \%$ prevalence [123]. Badaracco et al. [124] detected simultaneous oral-cervical infection in 5 of 29 patients (equal to $17.2 \%$ ) by means of a molecular technique called "strip-test" which combines PCR with Reverse Blot Hybridization. Recently, Giraldo et al. de- 
tected, once again by means of PCR, the presence of the virus in the oral mucosa in over $37 \%$ of patients with both cytological and histological lesions in the HPV-related genital area, a percentage which drastically drops to $4.3 \%$ in women without symptoms [125]. These results have led many authors to suggest that infection in the genital mucosa represents a condition which favours the progression of the viral infection of the oral mucosa, even if many studies have not found a genotypical concordance between the infection in the two areas. In Badaracco et al.'s study, in 3 of 5 cases of dual infection, HPV 16 was detected in both areas. In addition, some authors have highlighted, in a sample of women suffering from SCC of uterine cervix, a significant correlation of gt with cervicalvaginal infection. In 23 of 28 women with concurrent HPV genital infection, they detected the same gt found in the oral area, leading to the hypothesis that the virus, after primary infection in the inoculation site, is able to spread to other epithelial areas, i.e. the cervical mucosa, which is particularly susceptible to HPV infection and its oncogenic potential [126]. Smith et al [127] and Canadas et al. [33] instead, did not detect any genotypic oral-genital concordance in any of the patients examined. On the basis of this point and the fact that there is no corresponding infection in the partner, Smith et al. believed that both the possibility of infection through selfinoculation or by sexual transmission was unlikely, and therefore put forward the hypothesis of a different susceptibility to HPV infection in the two anatomic sites [127]. Canadas et al. were of the same opinion and assessed the many different areas where HPV infection may be present, (cervical, vaginal, vulvar, anal and oral mucosa) in a sample of high risk patients and they proposed a different affinity between the viral types compared in the two mucosal sites: in the anogenital area, infection caused by HPV HR was found in over $80 \%$ of cases, while in the oral cavity a predominance of HPV LR was detected [33]. The genotypic variability of the infection, which is commonly found even in monogamous partners, therefore, seems to depend on the differences relative to tissue characteristics and microbial flora of each mucosal site, even if other hypothesis must still be taken into consideration. In fact, some authors have linked the diverse anatomic susceptibility to different mechanisms of the immune system. In his study Goncalves et al. assumed that there was concordance between genital HPV infection and reduced concentration of $\operatorname{IgA}$ in saliva secretions, a condition which would explain the fall in the protective function of local antibodies and therefore would make the oral cavity more susceptible to colonization by the virus [128]. Other authors put forward the hypothesis that dual or multiple infections may depend on a genetic predisposition which is probably connected in some way, as recently suggested, to some HLA haplotypes, able to make the infection more susceptible individually and more likely to transform HPV-related lesions into malignant ones [129, 130]. In conclusion it is obviously necessary to carry out further research to clarify the frequency of the concomitant infection (oral and genital) in relation to possible risk factors and to social-behavioural variables, paying particular attention to sexual habits which lead to an increase in susceptibility to the infection. These studies presuppose a multidisciplinary synergy involving diverse medical specializations (dentists, gynaecologists, virologists) to establish new ways of preventing HPV infection through effective diagnosis and treatment.

\section{THERAPIES FOR HPV INFECTION AND HPV- RELATED LESIONS}

For many infectious diseases, it is evident that therapy is beneficial and that their eradication can be achieved by means of control and prevention of infection [131]. Conversely for HPV-related lesions, these considerations are not similarly correct. No current therapy is able to eradicate the HPV infection and the available therapeutic tools have a limited impact in preventing lesion recurrence and reducing the likelihood of viral transmission. Following the current therapies for HPV-related lesions in genital and oral mucosa are described (see Table $\mathbf{3}$ ).

\subsection{Management of Genital HPV Infection}

None therapy is currently available and recommended for subclinical genital HPV infection, since this condition is not definable as a disease and it is usually transitory and self-eliminating by the host immune system over 6-20 months (usually 8-10 months). It is imperative to carry out the follow up of the condition and the repetition of HPV DNA test after this interval to verify the elimination of the infection, especially when sustained by HR HPV, potentially able to give a persistent and transforming infection [19, 37]. In addition adequate education and counselling of the infected patients is mandatory in order to control the horizontal transmission of infection and/or autoinoculation at other epithelial sites of the body. Because HPV infection is highly contagious, current sexual partner of infected subjects are likely already HPV-infected. Condom use may reduce partially the risk of transmission because the virus is able to infect the epithelium of the entire anogenital tract. Routine clinical and virological examination of sexual partners is not mandatory $[132,133]$. On the other hand, female sex partners of male patients who have genital infection/warts should be reminded that cytological screening for cervical cancer is recommended; in fact among men, genital infection is more frequently unapparent than in women, where more frequently genital/cervical infection is associated with asymptomatic lesions [134].

In presence of HPV-related lesions, the treatment is based on surgery, local or systemic administration of drugs (cytotoxic or immunomodulatory agents) or a combination of all of them [135] (Table 3). The decision whether to treat HPV-related lesions is strongly influenced by the clinical manifestations, symptoms and the potential malignancy. Genital warts and condylomas are associated with discomfort and physical/psychological dysfunctions; although eradication of infection is not feasible, treatment of these benign lesions is warranted in order to reduce these negative aspects. However, before starting therapy, patients should be learned about the limitations of the current available therapy for genital warts/condylomas, because most of these are effective in clearing warts or temporary reducing their size, but recurrence rates are high after all treatments [131].

Surgical, ablative and destructive therapy. Surgery remains the basic method for the treatment of the most frequent HPV-related anogenital lesions. The excision may be performed using cold knife, electrosurgery or laser after local anaesthesia. For anogenital warts and condylomas the standard therapy is the destruction of the lesion with cryosurgery, cryotherapy with liquid nitrogen, laser ablation (CO2) or electrocautery [135]. Other modalities of aspecific destruction of external benignant lesions are based on the typical application of acids (mono-, bi- and trichloroacetic acids MCA, BCA, TCA respectively - and salicylic acid), or aldehydes (glutaraldehyde, formaldehyde). As for cryotherapy, the response rate range from $50-80 \%$ and about one-fourth of patients has a relapse. The photodynamic therapy, based on the local application of photosensitizer agents (derived from porphyrins) selectively uptaken by tumor cells, have been tested for HPV-related lesion, especially RRP, and successively for genital lesions (CIN, VuIN), with a response in about $50 \%$ of cases according Martin-Hirsch et al [136, 137]. Nevertheless, results of more recent studies were contrasting, also for RRP [138, 139].

A specific treatment has been recommended for CIN, that is the application of the LLETZ (Large Loop Excision of Transformation Zone), derived from the Loop Electrode Excision procedure (LEEP) and associated with greater safety and efficacy (95\% cure rate in a year) and minor recurrence rates than other surgical procedures $[135,140]$. Other potentially malignant lesions of anogenital area (AIN, VaIN, VuIN, PIN) represent challenging clinical problems because there are no standard surgical recommendations as for CIN lesions [141]. Noteworthy, tobacco smoking represents a well known co-carcinogenic agent for development of these HPV-related diseases, so dedicated education and counselling for smoking cessa- 
Table 3. Management of HPV Infection/Diseases in Genital and Oral Mucosa

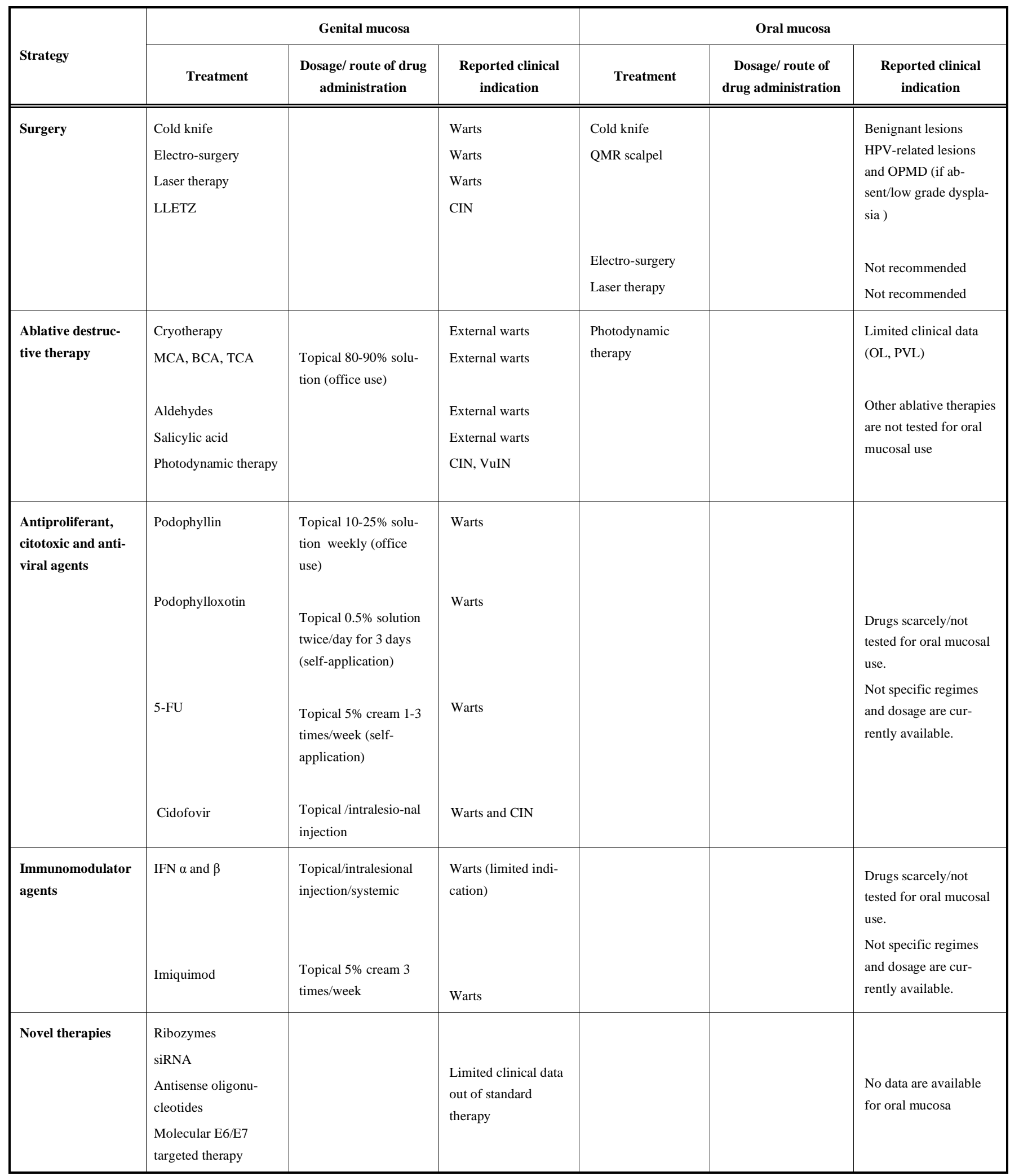

tion in patients who smoke are required [19, 131]. A more detailed discussion of the treatment of anogenital intraepithelial neoplasia and SCC is not the aim of this review and we forward to dedicated gynaecological literature.
A significant proportion (about 50\%) of patients treated in first line with surgery (especially with traditional cold knife technique or ablative therapy) are subjected to a recurrence and need of an adjuvant medical treatment [142, 143]. Moreover ablative approaches 
have significant sequelae such as bleeding, scarring, pain and inflammation. In addition, when visible lesions are effectively removed, residual viral particles or DNA in surrounding tissues may reseed the treated site and lead to recurrence of lesion. A series of medical therapies have been proposed, as following reported.

Antiproliferative, cytotoxic and antiviral agents. These drugs play as metabolic inhibitors when topically applied or injected into visible lesions. Podophyllin, resin extracted from the roots of some Berberiacee species, are a cytotoxic agents able to arrest mitosis at metaphase by binding tubulin and also to destroy HPV virions. It was abandoned in favour of its derived podophyllotoxin (also known as podofilox), associated with minor local and systemic side effects, indicated for topical treatment of external genital warts (0.5\% solution) [144] (Table 3). 5-Flururoacil (5-FU) inhibit DNA and RNA synthesis and acts as antimetabolite when used topically as $5 \%$ cream for self-application for treatment of multifocal and extensive genital warts or VaIN/ VuIN, although its use is recently restricted because frequently cause local irritation [144]. Bleomycin, able to bind DNA, is not indicated for mucosal lesions because intralesional injection is very painful and associated with local side effects (swelling and eschar formation) [145]. Cidofovir is a nucleotide analogue (acylic nucleoside phosphonate) able to inhibit DNA synthesis and, according some reports, may induce apoptosis [146]. It has a broad spectrum antiviral activity against several DNA viruses. However, the rational for using cidofovir for the treatment of HPV-related lesions is not clear since the HPV replicative cycle is completely different from other DNA viruses sensitive to this molecule, so the question remains if the activity of cidofovir against HPV produces more antiproliferative than antiviral effects. Its clinical use as topical cream or injected solution, intralesionally or systemically, has been tested in several HPV-related lesions (anogenital condylomas, skin warts, CIN, recurrent respiratory papillomatosis) with success [147], also among immunocompromised patients [148] and as co-adjuvant agents to ablative and/or surgical removal to reduce relapse [149]. However large randomized clinical trials are still not available, thus different questions (about the exact mechanism of action, the treatment modalities, the response rate and the suspected carcinogenic potential of the molecule) still remain [150].

Immunomodulatory drugs. While previous strategies act indiscriminately destroying both healthy and infected tissues, approach with immunomodulatory agents consent to enhance the host immune response in order to organize a selective defence to HPV infected cells. This effect may be obtained directly by local application of interferon (IFN), or, indirectly, by administration of imiquimod. IFN $\alpha$ and $\beta$, playing both immunomodulatory and direct antiviral activity, were used alone or in association with other drugs for treatment of several HPV-related lesions, especially when difficult to treat with surgery, such as RRP [141]. IFN may be used with several routes of administration (topical application, intralesional injection, systemic), but the variable efficacy results with frequent rebound phenomenon at the end of therapy [151], the high costs and the frequent systemic side effects (i.e. leukopenia, fever, headheache, myalgia, asthenia), have progressively limited the use of these molecules [144]. Imiquimod, a member of the class of imidazquinolines, acts as a potent immunostimulator, antiviral and antitumoral agents in animal model. Imiquimod demonstrated able to induce the release of pro-inflammatory Th1 class cytokines from lymphocytes and macrophages (e.g. IFN- $\alpha,-\beta$ and $-\gamma, \mathrm{TNF} \alpha$ and IL12) and to enhance cell-mediated local immunity against viral targets, mechanisms that may facilitate viral clearance. It has been indicated topically $(5 \%$ cream) for the treatment of genital warts $[131,152,153]$ recently, some case series test its efficacy in patients with VuIN [154], AIN [155], carcinoma in situ of the penis [156]. Imiquimod is well tolerated, only mild to moderate local side effects (inflammation) have been reported, but the not conclusive results of reported small sized studies and lack of large series and/or RCT and have reduced the use of this agent.

Very recently Roberts et al. [157] reported interesting findings about the topical use of carrageenan to reduce susceptibility to HPV of cervical mucosa during cytology screening. The same molecule have been proposed as adjuvant to peptide-based vaccine for their ability to induce antigen specific immune response, especially against E7 [158].

Noteworthy, an important limitation of the immune-modulatory therapy is that the viral replicative cycle and the protein transcription in the infected cells entirely occur into the nucleus and the cytoplasm, without expression of viral protein on the cellular membrane, in this way infection happens without immune response activation. Moreover the viral oncoproteins E6 and E7 have specific mechanisms for abrogate the host immune response [159]. These two mechanisms may explain the variable efficacy of immunetherapies in different patients in presence of specific HPV genotypes.

New therapeutic strategies. The new therapeutic challenge is the development of more targeted strategies based on nucleic acids (small interfering RNA, antisense oligonucleotides, and ribozymes able to inhibit expression or activity of viral proteins) [159, 160]. E6 and E7 proteins demonstrated to play together to nullify host immune responses, thus interdicting E6- and E7- mediated actions could increase the likelihood of infection elimination by the natural immunity.

For E6 targeting therapy, the abrogation of telomerase activity and the interdiction of E6-p300/CBP interaction have been studied [159, 161-164].

For E7 targeting strategy, potentially candidate for therapeutic intervention is the interaction of E7 proteins with cdk inhibitors (CKIs: $\mathrm{p} 21^{\mathrm{CIP} 1}$ and $\mathrm{p} 27^{\mathrm{KIP} 1}$ ) and the disruption of the E7-IRF-1 complex and/or inhibition of HDAC activity [159, 165, 166].

In addition numerous other interaction between HPV E/L proteins and host regulatory factors have been recognized are still studied for molecular targeted strategy (reviewed in [159, 167]), nevertheless the use of this approach is still a promising strategy that will require further exploration.

\subsection{Management of Oral HPV Infection}

As discussed with respect to genital HPV infection, also in oral cavity HPV subclinical infection does not need of treatment since any tested antiviral drugs (e.g. acyclovir, ribavirin) have been demonstrated able to eliminate the infection [135] (Table 3). The management of this condition is based on the follow up of the patient over at least 8-12 months, repetition of HPV DNA test after this interval and periodically until elimination of the infection occurs. As assumed for gynaecology field, a persistent viral status (sustained by HR-HPV types) maintained for at least 2 years represents a necessary although not sufficient basis for HPV-related lesions $[46,47,85,168]$. Differently by gynaecologists, employing a standard sampling method for HPV testing in uterine cervix, in oral medicine a uniform method of specimens collection for HPV detection still does not exist. Several procedures of oral specimens collection were evaluated in literature $[169,170]$. However, the virus is rarely found in oral mucosa, probably due to saliva clearance. Potentially, it is more probable that tonsillar crypts and the glottides, more susceptible to viral entry and replication [171], will constantly harbour virions than other mucosal oral districts, and they will be detected with greater difficultly. Furthermore, in most studies, the exact anatomic sites of the samples are not given and thus, the origin of HPV infection (whether oral or oropharyngeal) is impossible to trace.

The samples are taken either as mucosal scrapings, oral rinses or tissue biopsies. The biopsy remains one of the most common procedures of oral sampling, thanks to the possibility of using the 
same specimen for morphological examination as well as for the HPV test, also in different timing. The biopsy, moreover, provides a more representative sample of oral mucosa as compared with exfoliative cytology and includes cells from the basal layer, where the virus could be present in a latent form. On the other hand, the exfoliative cytology is less invasive than a biopsy, especially in absence of lesions, allows to harvest cells from a greater surface area and involve minor chance of contamination before DNA extraction than a surgical procedure $[76,172,173]$. When a scraping is taken from an keratinized mucosa (similar as the skin) (e.g. hard palate, gum), the sample is frequently inadequate due to the low number of nucleated cells. Overall, the HPV detection rate is higher in oral rinse samples $(12-51 \%)$ and oral scrapings $(45 \%)$ than in brush samples from the tonsils (3\%) or biopsies (12\%) [31, 174-176].

Lately, the oral rinse was proposed as method of cytological sampling more efficient than the superficial brushing/scraping of oral mucosa in terms of DNA yield, quality and stability, as well as acceptability by the sample donor [177, 178]. In oral rinse, however, the majority of HPV-positive cells might origin from the oropharynx and tonsils. A recent meta-analysis on oral and oropharyngeal cancers showed that a representative biopsy from the lesion resulted in the highest HPV detection rates especially when PCR was used (29.8\% versus 38.1\%) [179]. Not only the sampling itself, but also the technical aspects in sample processing are of importance e.g. the sample transport media, storage time and temperature. For example in saliva, there are some 10 million bacteria/ml which might compromise HPV testing. The media used for HPV testing of oral scrapings include the same transport media as used also for cervical samples (usually slightly alkaline buffers with antibiotics), ethanol [23-25, 180, 181] or mouth wash [182].

The sensitivity and specificity of the HPV testing method as well as the expertise of the researchers in interpreting the results are of key importance in addition to sampling site and sample processing. In a previous study, it has been found that 3 sequential swabs from the buccal mucosa will result in approx. 100.000 cells which is optimal for HPV testing [175]. In these samples, HPV detection rate was related to the sensitivity of the HPV testing method; HPV DNA was found in $3.8 \%, 15.6 \%$ and $23.1 \%$ with dot blot hybridization, Southern blot hybridization and PCR, respectively [31, 175]. An important aspect frequently neglected is the quality of DNA for PCR, particularly because the microbe load is so high in saliva. A purified DNA will result in much higher HPV detection rate than non-purified DNA, as shown by us already in 1997 [180, 181], and confirmed by D'Souza and co-workers in 2005 [182]. Nested PCR will increase HPV detection rate and should be used especially when the cell count in the sample is not optimal. In our Finnish Family HPV Study, we have used nested PCR with subsequent hybridization. With this method, we found high-risk HPVs in $16 \%$ to $27 \%$ of the oral scrapings taken in $80 \%$ ethanol. DNA extraction was made with the high salt method [23-25]. Similarly, Kay et al 2002 reported that HPV detection rate in buccal swabs increased from $19 \%$ to $74 \%$ when single PCR with MY09/11 primers was replaced by nested PCR with MY09/11 and GP05+/06+ primers [183].

Very important are also the counselling about tobacco smoking/alcohol drinking cessation and education about hygiene and sexual practices (in terms of dishes sharing and direct contact with other individuals). About association with common risk factors, has been described that alcohol abuse increases the risk of HPV infection, especially among OSCC patients [184, 185].

Smith et al. [177] demonstrated that alcohol had an independent and synergistic effect with HPV increasing the risk of viral persistence and cancer development. It is biologically plausible that an interaction effect between HPV and alcohol may occur: alcohol could biologically modify mucosal tissue, potentially increasing its permeability to viral infection, or it could influence the immune response to HPV [186]. Although some studies have reported con- trasting results about the association between HPV infection and alcohol $[6,43,187,188]$ and it deserves to be better investigated, advocating patients in alcohol abuse cessation is recommended. The same recommendation are true for tobacco smoking; although not uniform results was reported until now, the recent large study of Sanders et al reported a prevalence of HPV infection in current smokers more than twice that of non-smokers $(12.7 \%$ vs. $5.1 \%)$, with a dose-related response confirmed also by serum cotinine concentration [6]. Noteworthy is also the elimination of any trauma (fractured teeth, restorations with cutting margins, incongruous prostheses), since a previous study reported an unexpected high frequency (about 26\%) of HPV DNA detection in benignant oral erosive-ulcerative lesions (EULs) of probably traumatic origin [43]. HPV infection could be due to the oral lesion per se, similarly to findings in the genital mucosa, where mechanical trauma can lead to epithelial basal cell exposure and subsequent HPV entry and replication. This preliminary datum, if substantiated by studies with larger numbers of patients, could have both screening and etiologic implications since long-term follow-up of patients with a history of HPV-positive EULs could be helpful in evaluating any clinically different behaviour (tendency to persistence or recurrence or likelihood of progression to premalignant stages), compared with HPVnegative EULs.

Regarding the hygienic and sexual practices, sexual behavior is strongly indicative of HPV infective status also in oral cavity, in terms of early sexual debut and multiple sexual partners. Odds for HPV detection were found by Sanders et al in U.S. population about 10 times greater among individuals reporting 20 or more lifetime sexual partners compared to these with less than 3 partners. Because divorced/separated individuals had greater OR of HPV infection than married, the authors have postulated that single status is indicative of higher number of sexual partners. The possibility of auto-infection among women with cervical HPV infection is still a matter of debate $[189,190]$. In a recent metanalysis, prevalence of concurrent oral and genital HPV infection among women was estimated to be $18.1 \%$, with a type-specific concordance in $27 \%$ of bifocal infection $(p=0.002)$, and this evidence was found more strong among HIV infected women [189]. Furthermore, oral sex, including fellatio and cunnilingus, has being hypothesized as the main way of transmission for oral HPV infection. Recently, HPV was detected more commonly in biopsy specimens from cancer patients with more than one sexual partner and from those who practiced oral sex than in biopsy specimens from those who did not engage in oral sex, thereby confirming the possibility of oral transmission [191]. However, mouth-to-mouth transmission, for example through kissing, still remains possible and it should not be excluded as a route of oral HPV transmission. Since the onset of the HIV epidemic, an increase in oral sex among teenagers and young adults has been observed, probably because this is thought to represent a form of safe sex. However, oral sex is not risk free and it can result in HPV-related HNSCC. According to recent epidemiological data, a different segment of population in now at risk of HNSCC, especially OPSCC, i.e. young Caucasian males $[9,192]$ have estimated that if the current incidence trend will continues, the annual number of HPV-positive OPSCC might exceed the annual number of CSCC by 2020. Public education is of paramount importance: there is a need to disseminate these findings and to place them in context.

If a given HPV-related lesions is present, the treatment is based mainly on surgery, since local or systemic applications of medications (cytotoxic or immunomodulatory drugs) were extensively tested in head and neck district only for RRP, as above reported, and not for oral mucosal lesions. Recently, an experimental study has tested a bio-adhesive patch system releasing imiquimod for the topical treatment of dysplastic and neoplastic lesions (dosecontrolled topical delivery) that may allow to extend the clinical uses of this immunomodulatory agent to the treatment of potentially 
malignant lesions conditions of oral as well genital mucosa recognized to be HPV- infected [193].

Surgical therapy. The excision of the lesions, associated with HPV DNA test (usually performed in epithelial cells collected by oral rinse/brushing before surgery or in formalin-fixed/paraffinembedded or fresh frozen histological samples) could be carried out after local anaesthesia by traditional cold knife, quantic molecular resonance (QMR) scalpel [194] or electro-surgery. The last technique could influence negatively the histological examination, especially in presence of small sized lesions, because of cauterization of margins of the samples. Likewise, since the laser ablation of HPV-related lesions is to discourage, since the histological diagnosis is essential to distinguish each HPV-related lesion from the others HPV-unrelated with similar clinical presentation and to identify any grade of epithelial dysplasia, if present.

In presence of lesions sized more than $2 \mathrm{~cm}$ or multifocal, especially if a PMD or carcinoma in situ/OSCC is suspected, an incisional single or multiple biopsy is recommended, eventually preceded by mapping with a vital colorant (Toluidine blue) or a visual device (e.g. VelScope ${ }^{\circledR}$, Sapphire $\left.{ }^{\circledR}\right)$. The complete excision of the lesion should be postponed after histological diagnosis and diversified on the basis of the presence and degree of dysplasia or carcinoma. However, the patients should be informed that, in light of the multifocal nature of oral and oropharyngeal infection, surgical removal of the lesion does not guarantee elimination of infection, because viral DNA could persist in normal adjacent mucosa [174].

\section{New Perspectives for Management of OPMDs/OSCC/OPSCC and HPV Infection}

About prognosis of HPV-infected OPMDs and carcinoma, some questions still raise: while it is very doubtful if HPV could influence the malignant progression of OPMDs [12, 195], with respect to OPSCC and OSCC, recent clinical data in the literature confirm that HPV infection represents the most significant positive prognostic factor. Furthermore, HPV 16 has been positively associated with a better response to chemo-radiation in OPSCC. The HPV-related OPSCC "epidemy" may give a possible explanation for the overall and disease-specific survival rates for SCC of tonsils and base on tongue, regardless of stage at diagnosis and type of therapy [196-199]. This evidence may have important clinical and therapeutic consequences, since the routinely detection of p16 as a surrogate marker or HPV DNA directly should be performed and considered as a key factor in the decision-making process of treatment [200, 201]. However, we are unable to make the same suggestion for the OSCC. Currently a case-control observational casecontrol perspective study is in progress entitled "Biomarkers of immune function as predictors of head and neck squamous cell carcinoma (HNSCC) in response to therapy" (registered on ClinicalTrials.gov Archive Site, identifier code NCT01358097), by the recruitment of LSCC/OPSCC positive and negative for HPV versus normal healthy volunteers. The purpose of that study is to investigate the role of the immune system in the response of HNSCC to treatment with respect of HPV infection. The investigators are testing the hypothesis that radiation-based therapy of OPSCC is associated with activation of the endogenous HPV-specific immune response. The results could provide valuable information to better understand the body's interaction with cancer cells and could suggest novel therapeutic approaches for HPV positive HNSCC. Noteworthy, during the last 2011 ASCO annual meeting (American Society of Clinical Oncology), several researchers have reported the different outcomes and response to therapy of OPSCCs HPVpositive vs. HPV-negative ones [202-204]. They have found independently a better survival and low locoregional failure rates following any modalities of treatments, including novel approaches as nonsurgical definitive radiotherapy (IMRT) and mini-invasive surgical approaches as TLM (transoral laser microsurgery) followed by post-operative chemo-radiotherapy. These results were obtained regardless the higher stages and the higher frequency of nodal me- tastases of HPV-positive than HPV-negative OPSCCs and further strengthen the option to consider HPV-status when planning prospective studies on treatment for base of tongue and tonsillar SCCs.

New therapeutic perspectives regard the opportunity to use HPV vaccines for targeted therapy of HPV-positive HNSCC cancer, especially OPSCC. Several researchers worldwide are still studying this challenging field: a clinical trial is in progress in UK at LTCU (Liverpool Cancer Trials Unit), named REALISTIC, on the efficacy and safety of a Recombinant Listeria Monocytogenes (Lm)-based vaccine encoding Human Papillomavirus Target Antigens (i.e.ADXS11-001) in patients With HPV-16-positive OPSCC. If proved safe, ADXS11-001 may be introduced as a post-treatment adjuvant as part of a treatment de-escalation strategy in an attempt to reduce the adverse effects of current treatment strategies without compromising survival (from web site http: //www.lctu.org.uk/ trial/trial_info.asp $\mathrm{id}=73 \& \operatorname{tg} \operatorname{code}=2 \&$ menuid=30). Another not randomized clinical trial is currently under way at Maryland University, with the aim to test a vaccines comprised on the Trojan peptides MAGE-A3 and HPV 16 for treating patients with HNSCC who have recurrent, progressive or metastatic tumours (study registered on ClinicalTrials.gov Archive Site, identifier number NCT00257738). Findings of this phase I open labels and, preferably of randomized clinical trials not yet performed, could contribute in the next future to the implementation of HPV-related HNSCC therapy, especially for base of tongue and tonsils SCC, in order to assure better prognosis, a surgery as conservative as possible and improved quality of life. On the basis of the lower evidence of a causative role of HPV in the development of other not site-specific OSCC, it is not possible forwarding these preliminary data to SCC located in oral cavity.

\section{PREVENTION OF HPV INFECTION: VACCINES}

To date, three preventive HPV vaccines have been developed and clinically evaluated in randomized clinical trials [205]:

i. monovalent HPV 16 vaccine (manufactured by Merck, Sharpe \& Dome, Whitehouse Station, NJ, USA);

ii. quadrivalent vaccine containing $\mathrm{L} 1$ protein of HPV $6,11,16$ and 18 (Gardasil®, produced by the same manufacturer);

iii. bivalent vaccine containing L1 of HPV 16 and 18 (Cervarix ${ }^{\circledR}$, produced by GlaxoSmith, Rixensart, Belgium).

The first vaccine has not been commercialized, while Gardasil® and Cervarix ${ }^{\circledR}$ were licensed by FDA (Food and Drug Administration) in U.S. in 2006 and 2009, respectively.

The quadrivalent vaccine was first licensed for use in females aged 9-26 years for prevention of cervical, vaginal and vulvar SCC and precursors (CIN, VaIN, VuIN) [206, 207]. Three years later, its use was extended to males in the same range of age because it was tested in males, being demonstrated effective against penile SCC [208], and lately FDA further enlarged the indication to prevention of AIN and anal SCC [206, 209]. Moreover the quadrivalent vaccine is approved for prophylaxis of genital warts/condylomas due to HPV low risk types 6 and 11. In clinical trials, Gardasil@ has demonstrated very high effective for prevention of all types of anogenital cancer precursors, either among naive-individuals (efficacy $>98 \%$ ) and HPV 6-11-16-18 infected patients (efficacy ranging from $50-78 \%$ ) [210, 211].

The bivalent vaccine has been tested only for cervical SCC and precursors, not for other HPV-related malignancies/premalignancies, and licensed for use in girls aged 10-26 years [212]. Like previous vaccine, Cervarix ${ }^{\circledR}$ has a very high efficacy in preventing HPV 16 and 18-related CINs and CSCCs, especially in naive subjects) among naive HPV16 and 18 subjects (>97\%) [211]. Nevertheless, based on the structural similarities between quadrivalent and bivalent vaccines, it is reasonable believing that also Cervarix ${ }^{\circledR}$ will also be effective for HPV 16 and 18 related lesions in other anatomical sites. 
Both HPV vaccines need of three doses, the first at day 1 , the second at month 1 for bivalent vaccine and month 2 for quadrivalent one, and the third at month 6 [213].

To date the vaccines are available in most European countries and in over 70 states worldwide; several developed countries have approved, after U.S., national HPV vaccination programs based on administration mainly of quadrivalent vaccine to 9-17 years old girls (i.e. Sweden, Italy, France, Netherland, Germany, Switzerland, Denmark, Spain, Belgium and other ones), with an overall acceptance rate of about 50\% [153, 214]. Program advantages are directed both to individuals receiving directly the vaccine (adolescent girls) and those who benefit from the so called herd immunity (when vaccinated susceptible individuals benefit from reduced HPV transmission induced by vaccination of other subjects, at least for HPV types covered by vaccines). It is noteworthy that, at population levels, to obtain successful herd immunity, vaccination should cover $80 \%$ of the population. In this context, vaccination programs including boys in addition to girls may be justified to pursuit this ambitious goals [215], although, the expensive cost could limit this approach in less developed or developing countries. Other crucial questions still raise: assessing the age of the first contact with the virus in order to give HPV vaccines to naive individuals and guarantee the greatest efficacy and the opportunity to extend the vaccination to homosexual males, to date not protected indirectly from reduced heterosexual transmission deriving for adolescent girls vaccination programs. The greater benefits obtainable through vaccination of this category of patients are more evident bearing in mind that they also frequently acquired HIV infection and so they are at high risk to HPV-related diseases, especially AIN and anal SCC.

While no direct evidence exists about the efficacy of the vaccines in reducing the acquisition and the expression of HR HPV in the oral cavity and oropharynx, once these vaccines are effective in anogenital region, it seems reasonable to believe that they may play against the same HPV types in other mucosal sites as well $[6,206]$. If proven to do so, these vaccines would represent a major breakthrough in preventing all HPV-related diseases, including OPSCC, and also providing the definitive evidence that HPV is the cause of these tumours. The impact of HPV vaccination programs on future cancer incidence will take decades, and the use of national cancer registries is essential to evaluate the outcomes on the epidemiology of HPV-related diseases (i.e. incidence rates of cervical, anogenital and oral/oropharyngeal SCCs and their precursors; incidence of benignant HPV-related lesions in all sites and, finally, vaccine safety) [216].

\section{CONCLUSIONS}

The last decades have produced very relevant growing of knowledge about the molecular steps in the life cycle of HPV, the biochemical properties of viral oncoproteins and remarkable progresses have been made about the diagnostic methods of HPV DNA detection. Understanding the interplay between HPV and host cell pathways provide many potential new targets for disrupting the viral infection process and for the development of novel viral specific therapies for HPV infection in oral cavity. To date, the best therapeutic management of oral HPV-related diseases, both benignant and potential malignant ones, is the surgery. Medical therapy, as topical and systemic drugs, has been tested for treatment of the most common genital lesions and of RRP, but not also for oral mucosal diseases. Furthermore, adequate campaigns of primary prevention (sexual education, vaccination programs) could lead to the control of the infection in oral and oropharyngeal tract similarly to genital districts. All these perspectives represent big challenges that will require several years as well as would hesitate in eradication of HPV-related malignant diseases.

\section{CONFLICT OF INTEREST}

The authors confirm that this article content has no conflicts of interest.

\section{ACKNOWLEDGEMENT}

None declared.

\section{REFERENCES}

[1] Bosh FX, Lorincz A, Munoz N, Meijer CJ, Shah KV. The causal relation between human papillomavirus and cervical cancer. J Clinical Pathol 2002; 55: 244-65.

[2] Cogliano V, Baan R, Straif K, Grosse Y, Secretan B, El Ghissassi F. Carcinogenicity of human papillomaviruses. Lancet Oncol 2005 6(4): 204.

[3] Bouvard V, Baan R, Straif K, et al. A review of human carcinogens--Part B: biological agents. Lancet Oncol 2009; 10(4): 321-2.

[4] Hariri S, Unger ER, Sternberg M, et al. Prevalence of genital human papillomavirus among females in the United States, the national health and nutrition examination survey, 2003-2006. J Infect Dis $2011 ; 204:$ 566-73.

[5] Dunne EF, Sternberg M, Markowitz LE, et al. Human Papillomavirus (HPV) 6, 11, 16, and 18 Prevalence Among Females in the United States--National Health and Nutrition Examination Survey, 2003-2006: Opportunity to Measure HPV Vaccine Impact? J Infect Dis 2011; 204: 562-5.

[6] Sanders AE, Slade GD, Patton LL. National prevalence of oral HPV infection and related risk factors in the U.S. adult population. Oral Dis 2011(Accepted manuscript DOI: 10.1111/j.16010825.2011.01892.x).

[7] Gillison ML, Broutian T, Pickard RK, et al. Prevalence of Oral HPV Infection in the United States, 2009-2010. JAMA 2012; 307(7): 693-703.

[8] Sturgis EM, Cinciripini PM. Trends in head and neck cancer incidence in relation to smoking prevalence: an emerging epidemic of human papillomavirus-associated cancers? Cancer 2007; 110(7): 1429-35.

[9] Chaturvedi AK, Engels EA, Anderson WF, Gillison ML. Incidence trends for human papillomavirus-related and -unrelated oral squamous cell carcinomas in the United States. J Clin Oncol 2008; 26(4): 612-9.

[10] Nasman A, Attner P, Hammarstedt L, et al. Incidence of human papillomavirus (HPV) positive tonsillar carcinoma in Stockholm, Sweden: an epidemic of viral-induced carcinoma? Int $\mathrm{J}$ Cancer 2009; 125(2): 362-6.

[11] D'Souza G, Kreimer AR, Viscidi R, et al. Case-control study of human papillomavirus and oropharyngeal cancer. N Engl J Med 2007; 356(19): 1944-56.

[12] Syrjanen S, Lodi G, von Bultzingslowen I, et al. Human papillomaviruses in oral carcinoma and oral potentially malignant disorders: a systematic review. Oral Dis 2011; 17(1): 58-72.

[13] Reid R, Campion MJ. The biology and significance of human papillomavirus infections in the genital tract. Yale J Biol Med 1988; 61(4): 307-25.

[14] Cobb MW. Human papillomavirus infection. J Am Acad Dermatol 1990; 22(4): 547-66.

[15] Howley PM. Role of the human papillomaviruses in human cancer. Cancer Res 1991; 51(18 Suppl): 5019s-22s.

[16] McKaig RG, Baric RS, Olshan AF. Human papillomavirus and head and neck cancer: epidemiology and molecular biology. Head Neck 1998; 20(3): 250-65.

[17] de Villiers EM, Fauquet C, Broker TR, Bernard HU, zur Hausen H. Classification of papillomaviruses. Virology 2004; 324(1): 17-27.

[18] Rautava J, Syrjanen S. Human papillomavirus infections in the oral mucosa. J Am Dental Assoc (1939) 2011; 142(8): 905-14.

[19] Longworth MS, Laimins LA. Pathogenesis of human papillomavirus in differentiating epithelia. Microbiol Mol Biol Rev 2004; 68: 362-72.

[20] Femiano F. [Papilloma virus. Note I: identification and related oral pathology. Review of the literature]. Minerva Stomatol 2000; 49(6): 281-92. I papilloma virus. Nota I: Identificazione e patologie orali correlate. Revisione della letteratura.

[21] Deacon JM, Evans CD, Yule R, et al. Sexual behaviour and smoking as determinants of cervical HPV infection and of CIN3 among 
those infected: a case-control study nested within the Manchester cohort. Br J Cancer 2000; 83(11): 1565-72.

[22] Baseman JG, Koutsky LA. The epidemiology of human papillomavirus infections. J Clin Virol 2005; 32 Suppl 1: S16-24.

[23] Rintala MA, Grenman SE, Jarvenkyla ME, Syrjanen KJ, Syrjanen SM. High-risk types of human papillomavirus (HPV) DNA in oral and genital mucosa of infants during their first 3 years of life: experience from the Finnish HPV Family Study. Clin Infect Dis 2005; 41(12): 1728-33.

[24] Rintala MA, Grenman SE, Puranen MH, et al. Transmission of high-risk human papillomavirus (HPV) between parents and infant: a prospective study of HPV in families in Finland. J Clin Microbiol 2005; 43(1): 376-81.

[25] Rintala M, Grenman S, Puranen M, Syrjanen S. Natural history of oral papillomavirus infections in spouses: a prospective Finnish HPV Family Study. J Clin Virol 2006; 35(1): 89-94.

[26] Giraldo P, Goncalves AKS, Pereira SA, Barros-Mazon S, Gondo ML, Witkin SS. Human papillomavirus in the oral mucosa of women with genital human papillomavirus lesions. Eur J Obstet Gynecol Reprod Biol 2006; 126: 104-6.

[27] Syrjänen S, Puranen M. HPV infections in children: the potential role of maternal transmission. Crit Rev Oral Biol Med 2000; 11: 259-74.

[28] Kumaraswamy KL, Vidhya M. Human papilloma virus and oral infections: an update. J Cancer Res Ther 2011; 7(2): 120-7.

[29] Castellsague X, Drudis T, Canadas MP, et al. Human Papillomavirus (HPV) infection in pregnant women and mother-to-child transmission of genital HPV genotypes: a prospective study in Spain. BMC Infect Dis 2009; 9: 74.

[30] D'Souza G, Agrawal Y, Halpern J, Bodison S, Gillison ML. Oral sexual behaviors associated with prevalent oral human papillomavirus infection. J Infect Dis 2009; 199(9): 1263-9.

[31] Kellokoski JK, Syrjanen SM, Chang F, Yliskoski M, Syrjanen KJ. Southern blot hybridization and PCR in detection of oral human papillomavirus (HPV) infections in women with genital HPV infections. J Oral Pathol Med 1992 b; 21(10): 459-64.

[32] Smith EM, Ritchie JM, Yankowitz J, et al. Human papillomavirus prevalence and types in newborns and parents: concordance and modes of transmission. Sex Transm Dis 2004; 31(1): 57-62.

[33] Canadas MP, Bosch FX, Junquera ML, et al. Concordance of prevalence of human papillomavirus DNA in anogenital and oral infections in a high-risk population. J Clin Microbiol 2004; 42(3): 1330-2.

[34] D'Souza G, Fakhry C, Sugar EA, et al. Six-month natural history of oral versus cervical human papillomavirus infection. Int $\mathrm{J}$ Cancer 2007; 121(1): 143-50.

[35] Chang F, Shen Q, Zhou J, et al. Detection of human papillomavirus DNA in cytologic specimens derived from esophageal precancer lesions and cancer. Scandinavian J Gastroenterol 1990; 25(4): 3838.

[36] Chang F, Syrjanen S, Shen Q, Ji H, Syrjanen K. Detection of human papillomavirus (HPV) in genital warts and carcinomas by DNA in situ hybridization in Chinese patients. Cytopathology 1990; 1(2): 97-103.

[37] Burd EM. Human papillomavirus and cervical cancer. Clin Microbiol Rev 2003; 16(1): 1-17.

[38] zur Hausen H. Papillomavirus infections--a major cause of human cancers. Biochim Biophys Acta 1996; 1288(2): F55-78.

[39] Pillai MR, Phanidhara A, Kesari AL, Nair P, Nair MK. Cellular manifestations of human papillomavirus infection in the oral mucosa. J Surg Oncol 1999; 71(1): 10-5.

[40] Badaracco G, Venuti A, Morello R, Muller A, Marcante ML. Human papillomavirus in head and neck carcinomas: prevalence, physical status and relationship with clinical/pathological parameters. Anticancer Res 2000; 20(2B): 1301-5.

[41] Pillai MR, Nair MK. Development of a condemned mucosa syndrome and pathogenesis of human papillomavirus-associated upper aerodigestive tract and uterine cervical tumors. Exp Mol Pathol 2000; 69(3): 233-41.

[42] Miller CS, Johnstone BM. Human papillomavirus as a risk factor for oral squamous cell carcinoma: a meta-analysis, 1982-1997. Oral Surg Oral Med Oral Pathol Oral Radiol Endod 2001; 91(6): 62235 .

[43] Giovannelli L, Campisi G, Lama A, et al. Human papillomavirus DNA in oral mucosal lesions. J Infect Dis 2002; 185(6): 833-6.
[44] Centurioni MG, Puppo A, Merlo DF, et al. Prevalence of human papillomavirus cervical infection in an Italian asymptomatic population. BMC Infect Dis 2005; 5: 77.

[45] Ponten J, Guo Z. Precancer of the human cervix. Cancer Surv 1998; 32: 201-29.

[46] Snijders PJ, Steenbergen RD, Heideman DA, Meijer CJ. HPVmediated cervical carcinogenesis: concepts and clinical implications. J Pathol 2006; 208(2): 152-64.

[47] Syrjanen S, Shabalova I, Petrovichev N, et al. Age-specific incidence and clearance of high-risk human papillomavirus infections in women in the former Soviet Union. Int J STD AIDS 2005; 16(3): 217-23.

[48] Clifford GM, Goncalves MA, Franceschi S. Human papillomavirus types among women infected with HIV: a meta-analysis. AIDS (London, England) 2006; 20(18): 2337-44.

[49] Majewski S, Jablonska S. Immunology of HPV infection and HPVassociated tumors. International J dermatology 1998; 37(2): 81-95.

[50] Cavalcanti SM, Zardo LG, Passos MR, Oliveira LH. Epidemiological aspects of human papillomavirus infection and cervical cancer in Brazil. J Infect 2000; 40(1): 80-7.

[51] Beby-Defaux A, Bourgoin A, Ragot S, et al. Human papillomavirus infection of the cervix uteri in women attending a Health Examination Center of the French social security. J Med Virol 2004; 73(2): 262-8

[52] Tonon SA, Picconi MA, Zinovich JB, et al. [Prevalence of cervical infection by human papilloma virus (HPV) in the Caucasian and Guarani populations residing in the province of Misiones, Argentina]. Revista Argentina de microbiologia 2003; 35(4): 205-13.

[53] Sellors JW, Karwalajtys TL, Kaczorowski J, et al. Incidence, clearance and predictors of human papillomavirus infection in women. CMAJ 2003; 168(4): 421-5.

[54] de Sanjose S, Bosch FX, Tafur LA, et al. Clearance of HPV infection in middle aged men and women after 9 years' follow up. Sex Transm Infect 2003; 79(4): 348 .

[55] Munoz N, Bosch FX, de Sanjose S, et al. Epidemiologic classification of human papillomavirus types associated with cervical cancer. N Engl J Med 2003; 348(6): 518-27.

[56] Syrjanen S, Shabalova I, Petrovichev N, et al. Factors predicting persistence of high-risk human papillomavirus (HPV) infections in women prospectively followed-up in three New Independent States (NIS) of the former Soviet Union. Eur J Gynaecol Oncol 2005; 26(5): 491-8.

[57] Altinay-Kirli E, Güçer S, Karnak I. Perianal giant condyloma acuminata in an infant: an alarming lesion for a pediatric surgeon. Turk J Pediatr 2011; 53(3): 333-6.

[58] Scarbrough Lefebvre CD, Van Kriekinge G, Goncalves MA, de Sanjose S. Appraisal of the burden of genital warts from a healthcare and individual patient perspective. Public health 2011; 125(7): 464-75.

[59] Kreimer AR, Bhatia RK, Messeguer AL, Gonzalez P, Herrero R, Giuliano AR. Oral human papillomavirus in healthy individuals: a systematic review of the literature. Sex Transm Dis 2010; 37(6): 386-91.

[60] An HJ, Cho NH, Lee SY, et al. Correlation of cervical carcinoma and precancerous lesions with human papillomavirus (HPV) genotypes detected with the HPV DNA chip microarray method. Cancer 2003; 97(7): 1672-80.

[61] Baseman JG, Koutsky LA. The epidemiology of human papillomavirus infections. J Clinical Virology 2005; 32 S: S16-S24.

[62] Ponten J, Z. G. Precancer of the human cervix. Cancer Surv 1998; 32: 201-29.

[63] Ishi K, Suzuki F, Yamasaki S, et al. Prevalence of human papillomavirus infection and correlation with cervical lesions in Japanese women. J Obstet Gynaecol Res 2004; 30(5): 380-5.

[64] Kraus I, Molden T, Erno LE, Skomedal H, Karlsen F, Hagmar B. Human papillomavirus oncogenic expression in the dysplastic portio; an investigation of biopsies from 190 cervical cones. Br J Cancer 2004; 90(7): 1407-13.

[65] Nair S, Pillai M. Human papillomavirus and disease mechanisms: relevance to oral and cervical cancers. Oral Diseases 2005; 11: 350-9.

[66] Scheurer ME, Tortolero-Lunay G, Adler-Storthzz K. Human papillomavirus infection: biology, epidemiology, and prevention. Int J Gynecol Cancer 2005; 15: 727-46. 
[67] zur Hausen H, de Villiers EM, Gissmann L. Papillomavirus infections and human genital cancer. Gynecol Oncol 1981; 12(2 Pt 2): S124-8.

[68] Wilczynski SP, Bergen S, Walker J, Liao SY, Pearlman LF. Human papillomaviruses and cervical cancer: analysis of histopsthological features associated with different viral types. Human Pathology 1988; 19(6): 697-704.

[69] Schwartz SM, Daling JR, Shera A, et al. Human papillomavirus and prognosis of invasive cervical cancer: a population-based study. J Clin Oncol 2001; 19(7): 1906-15.

[70] Premoli-De-Percoco G, Ramirez JL. High risk human papillomavirus in oral squamous carcinoma: evidence of risk factors in a Venezuelan rural population. Preliminary report. J Oral Pathol Med 2001; 30(6): 355-61.

[71] Andersson S, Larson B, Hjerpe A, et al. Adenocarcinoma of the uterine cervix: the presence of human papillomavirus and the method of detection. Acta Obstet Gynecol Scand 2003; 82(10): 960-5.

[72] Sugiyama M, Bhawal UK, Dohmen T, Ono S, Miyauchi M, Ishikawa T. Detection of human papillomavirus-16 and HPV-18 DNA in normal, dysplastic, and malignant oral epithelium. Oral Surg Oral Med Oral Pathol Oral Radiol Endod 2003; 95(5): 594-600.

[73] Terai M, Hashimoto K, Yoda K, Sata T. High prevalence of human papillomaviruses in the normal oral cavity of adults. Oral Microbiol Immunol 1999; 14(4): 201-5.

[74] Zhang ZY, Sdek P, Cao J, Chen WT. Human papillomavirus type 16 and 18 DNA in oral squamous cell carcinoma and normal mucosa. Int J Oral Maxillofac Surg 2004; 33(1): 71-4.

[75] Sand L, Jalouli J, Larsson PA, Hirsch JM. Human papilloma viruses in oral lesions. Anticancer Res 2000; 20(2B): 1183-8.

[76] Lawton G, Thomas S, Schonrock J, Monsour F, Frazer I. Human papillomaviruses in normal oral mucosa: a comparison of methods for sample collection. J Oral Pathol Med 1992; 21(6): 265-9.

[77] Miller CS, White DK. Human papillomavirus expression in oral mucosa, premalignant conditions, and squamous cell carcinoma: a retrospective review of the literature. Oral Surg Oral Med Oral Pathol Oral Radiol Endod 1996; 82(1): 57-68.

[78] Praetorius F. HPV-associated diseases of oral mucosa. Clin Dermatol $1997 ; 15(3): 399-413$.

[79] Bouda M, Gorgoulis VG, Kastrinakis NG, et al. "High risk" HPV types are frequently detected in potentially malignant and malignant oral lesions, but not in normal oral mucosa. Mod Pathol 2000; 13(6): 644-53.

[80] Kurose K, Terai M, Soedarsono N, et al. Low prevalence of HPV infection and its natural history in normal oral mucosa among volunteers on Miyako Island, Japan. Oral Surg Oral Med Oral Pathol Oral Radiol Endod 2004; 98(1): 91-6.

[81] Syrjänen K., Syrjänen, S. Papillomavirus infections in human disease. New York: Wiley \& Sons 2000; pp. 1-615.

[82] Kreimer AR, Villa A, Nyitray AG, et al. The epidemiology of oral HPV infection among a multinational sample of healthy men. Cancer Epidemiol Biomarkers Prev 2011; 20(1): 172-82.

[83] Henley JD, Summerlin D-J, Tomich CE. Condyloma acuminatum and condyloma-like lesions of the oral cavity: a study of 11 cases with an intraductal component. Histopathology 2004; 44: 216-21.

[84] Syrianen S. Human papillomavirus infections and oral tumors. Med Microbiol Immunol 2003; 192(3): 123-8.

[85] Scully C. Oral squamous cell carcinoma; from an hypothesis about a virus, to concern about possible sexual transmission. Oral Oncol 2002; 38(3): 227-34.

[86] Axéll T. A prevalence study of oral mucosal lesions in an adult Swedish population. Odontol Revy Suppl 1976; 36: 1-103.

[87] Castro TP, Bussoloti Filbo I. Prevalence of human papillomavirus (HPV) in oral cavity and oropharynx. Braz J Otorhinolaryngol 2006; 72(2): 272-82

[88] Chang F, Syrjanen S, Kellokoski J, Syrjanen K. Human papillomavirus (HPV) infections and their associations with oral disease. J Oral Pathol Med 1991; 20(7): 305-17.

[89] Syrjanen S. Human papillomavirus infections and oral tumors. Med Microbiol Immunol (Berl) 2003; 192(3): 123-8

[90] Syrjanen SM, Syrjanen KJ, Happonen RP, Lamberg MA. In situ DNA hybridization analysis of human papillomavirus (HPV) sequences in benign oral mucosal lesions. Arch Dermatol Res 1987; 279(8): 543-9.

[91] Varnai AD, Bollmann M, Bankfalvi A, et al. The prevalence and distribution of human papillomavirus genotypes in oral epithelial hyperplasia: proposal of a concept. J Oral Pathol Med 2009; 38(2): 181-7.

[92] (FONTEC). Fonstdtedc. Le precancerosi orali. Protocollo di diagnosi e terapia 1989.

[93] Gassenmaier A. [Papilloma virus DNA (HPV) in leukoplakial and cancerous alterations of the oral mucosa]. Dtsch Z Mund Kiefer Gesichtschir 1988; 12(2): 149-51.

[94] Gassenmaier A, Hornstein OP. Presence of human papillomavirus DNA in benign and precancerous oral leukoplakias and squamous cell carcinomas. Dermatologica 1988; 176(5): 224-33.

[95] Perrons C, Brink N, Jalal H, Watts P, Jelley R. The impact of high risk human papillomavirus testing in an inner London colposcopy clinic. J Med Virol 2005; 76(4): 576-82

[96] Palefsky JM, Silverman S, Jr., Abdel-Salaam M, Daniels TE, Greenspan JS. Association between proliferative verrucous leukoplakia and infection with human papillomavirus type 16. J Oral Pathol Med 1995; 24(5): 193-7.

[97] Shroyer KR, Greer RO, Jr. Detection of human papillomavirus DNA by in situ DNA hybridization and polymerase chain reaction in premalignant and malignant oral lesions. Oral Surg Oral Med Oral Pathol 1991; 71(6): 708-13.

[98] Axell T, Pindborg JJ, Smith CJ, van der Waal I. Oral white lesions with special reference to precancerous and tobacco- related lesions: conclusions of an international symposium held in Uppsala, Sweden, May 18-21 1994. International Collaborative Group on Oral White Lesions. J Oral Pathol Med 1996; 25(2): 49-54.

[99] Campisi G, Giovannelli L, Ammatuna P, et al. Proliferative verrucous vs conventional leukoplakia: no significantly increased risk of HPV infection. Oral Oncol 2004; 40(8): 835-40.

[100] Campisi G, Di Fede O, Giovannelli L, et al. Use of fuzzy neural networks in modeling relationships of HPV infection with apoptotic and proliferation markers in potentially malignant oral lesions. Oral Oncol 2005; 41(10): 994-1004.

[101] Szarka K, Tar I, Feher E, et al. Progressive increase of human papillomavirus carriage rates in potentially malignant and malignant oral disorders with increasing malignant potential. Oral Microbiol Immunol 2009; 24(4): 314-8.

[102] Fettig A, Pogrel MA, Silverman S, Jr., Bramanti TE, Da Costa M, Regezi JA. Proliferative verrucous leukoplakia of the gingiva. Oral Surg Oral Med Oral Pathol Oral Radiol Endod 2000; 90(6): 72330

[103] Silverman S, Jr., Gorsky M. Proliferative verrucous leukoplakia: a follow-up study of 54 cases. Oral Surg Oral Med Oral Pathol Oral Radiol Endod 1997; 84(2): 154-7.

[104] Mao EJ, Schwartz SM, Daling JR, Oda D, Tickman L, Beckmann AM. Human papilloma viruses and p53 mutations in normal premalignant and malignant oral epithelia. Int J Cancer 1996; 69(2): $152-8$.

[105] Warnakulasuriya S, Johnson NW, van der Waal I. Nomenclature and classification of potentially malignant disorders of the oral mucosa. J Oral Pathol Med 2007; 36(10): 575-80.

[106] Maitland NJ, Cox MF, Lynas C, Prime SS, Meanwell CA, Scully C. Detection of human papillomavirus DNA in biopsies of human oral tissue. Br J Cancer 1987; 56(3): 245-50.

[107] Cox M, Maitland N, Scully C. Human herpes simplex-1 and papillomavirus type 16 homologous DNA sequences in normal, potentially malignant and malignant oral mucosa. Eur J Cancer B Oral Oncol 1993; 29B(3): 215-9.

[108] Vesper M, Riethdorf S, Christoph E, Ruthke A, Schmelzle R, Loning T. [Detection of human papillomavirus (HVP)-DNA in oral manifestation of lichen planus]. Mund Kiefer Gesichtschir 1997; 1(3): 146-9.

[109] Jontell M, Watts S, Wallstrom M, Levin L, Sloberg K. Human papilloma virus in erosive oral lichen planus. J Oral Pathol Med 1990; 19(6): 273-7.

[110] Gonzalez-Moles MA, Rodriguez-Archilla A, Ruiz Avila I, Esteban F, Gonzalez-Moles S, Bravo M. Presence of HPV 16 sequences in oral lichen planus lesions. Bull Group Int Rech Sci Stomatol Odontol 1998; 40(2-3): 92-7.

[111] Campisi G, Giovannelli L, Arico P, et al. HPV DNA in clinically different variants of oral leukoplakia and lichen planus. Oral Surg Oral Med Oral Pathol Oral Radiol Endod 2004; 98(6): 705-11.

[112] Petti S. Diagnostic delay is not associated with advanced-stage oropharyngeal cancer. . Eur J Oral Sci 2010; 118: 210-2. 
[113] Shiboski CH, Schmidt BL, Jordan RC. Tongue and tonsil carcinoma: increasing trends in the U.S. population ages 20-44 years. Cancer 2005; 103(9): 1843-9.

[114] Gillison ML. Human papillomavirus-associated head and neck cancer is a distinct epidemiologic, clinical, and molecular entity. Semin Oncol 2004; 31(6): 744-54.

[115] Andrews E, Seaman WT, Webster-Cyriaque J. Oropharyngeal carcinoma in non-smokers and non-drinkers: A role for HPV. Oral Oncol 2009; 45(6): 486-91.

[116] Syrjanen K, Syrjanen S, Lamberg M, Pyrhonen S, Nuutinen J. Morphological and immunohistochemical evidence suggesting human papillomavirus (HPV) involvement in oral squamous cell carcinogenesis. Int J Oral Surg 1983; 12(6): 418-24.

[117] Nagpal JK, Patnaik S, Das BR. Prevalence of high-risk human papilloma virus types and its association with P53 codon 72 polymorphism in tobacco addicted oral squamous cell carcinoma (OSCC) patients of Eastern India. Int J Cancer 2002; 97(5): 649-53.

[118] D'Costa J, Saranath D, Dedhia P, Sanghvi V, Mehta AR. Detection of HPV-16 genome in human oral cancers and potentially malignant lesions from India. Oral Oncol 1998; 34(5): 413-20.

[119] Gillison ML, Koch WM, Capone RB, et al. Evidence for a causal association between human papillomavirus and a subset of head and neck cancers. J Natl Cancer Inst 2000; 92(9): 709-20.

[120] Erdmann J. Recent studies attempt to clarify relationship between oral cancer and human papillomavirus. J Natl Cancer Inst 2003; 95(9): 638-9.

[121] zur Hausen H. Papillomavirus and cancer: from basic studies to clinical application. Nat Rev Cancer 2002; 2: 342-50.

[122] Thompson IO, van der Bijl P, van Wyk CW, van Eyk AD. A comparative light-microscopic, electron-microscopic and chemical study of human vaginal and buccal epithelium. Arch Oral Biol 2001; 46(12): 1091-8.

[123] Kellokoski J, S. Syrjanen, et al. Dot blot hybridization in detection of human papillomavirus (HPV) infections in the oral cavity of women with genital HPV infections. Oral Microbiol Immunol 1992; 7: 19-23.

[124] Badaracco G, Venuti A, Di Lonardo A, et al. Concurrent HPV infection in oral and genital mucosa. J Oral Pathol Med 1998; 27(3): 130-4.

[125] Giraldo P, A. K. S. Goncalves, et al. Human Papillomavirus in the oral mucosa of women with genital human papillomavirus lesions. Eur J Obstet Gynecol Reprod Biol 2006; 126: 104-6.

[126] Premoli-De-Percoco G, Ramirez JL, Galindo I. Correlation between HPV types associated with oral squamous cell carcinoma and cervicovaginal cytology: An in situ hybridization study. Oral Surg Oral Med Oral Pathol Oral Radiol Endod 1998; 86(1): 77-81.

[127] Smith EM, J. M. Ritchie, et al. HPV prevalence and concordance in the cervix and oral cavity of pregnant women. Infect Dis Obstet Gynecol 2004; 12(2): 45-56.

[128] Gonçalves AKS, P. Giraldo, S. Barros-Mazon, M. L. Gondo, R. L. Amaral, C. Jacyntho. Secretory immunoglogulin A in saliva of women with oral and genital HPV infection. Eur J Obstet Gynecol Reprod Biol 2006; 124: 227-31.

[129] Burchell. A. N. RLW, et al. Chapter 6: Epidemiology and transmission dynamics of genital HPV infection. Vaccine 2006; 24 Suppl 3: S52-61

[130] Snijders PJ, R. D. Steenbergen, et al. HPV-mediated cervical carcinogenesis: concepts and clinical implications. J Pathol 2006; 208(2): 152-64.

[131] Zanotti KM, Belinson J. Update on the diagnosis and treatment of human papillomavirus infection. Clev Clin J Med 2002; 69(12): 948, 51-5, 56 passim.

[132] Ferenczy A, Mitao M, Nagai N, Silverstein SJ, Crum CP. Latent papillomavirus and recurring genital warts. N Engl J Med 1985; 313(13): 784-8.

[133] Hoover K, Friedman A, Montaño D, Kasprzyk D, Greek A, Hogben M. What about the partners of women with abnormal Pap or positive HPV tests? Sex Transm Dis 2009; 36(3): 141-6.

[134] Giovannelli L, Migliore MC, Capra G, et al. Penile, urethral, and seminal sampling for diagnosis of human papillomavirus infection in men. J Clin Microbiol 2007; 45(1): 248-51.

[135] Snoeck R. Papillomavirus and treatment. Antiviral Res 2006; 71(23): 181-91

[136] Martin-Hirsch P, Kitchener HC, Hampson IN. Photodynamic therapy of lower genital tract neoplasia. Gynecol Oncol 2002; 84(1): $187-9$.
[137] Martin-Hirsch PL, Whitehurst C, Buckley CH, Moore JV, Kitchener HC. Photodynamic treatment for lower genital tract intraepithelial neoplasia. Lancet 1998; 351(9113): 1403

[138] Shikowitz MJ, Abramson AL, Steinberg BM, et al. Clinical trial of photodynamic therapy with meso-tetra (hydroxyphenyl) chlorin for respiratory papillomatosis. Arch Otolaryngol Head Neck Surg 2005; 131(2): 99-105.

[139] Snoeck R, Andrei G, De Clercq E. Specific therapies for human papilloma virus infections. Curr Opin Infect Dis 1998; 11(6): 7337.

[140] Bigrigg A, Haffenden DK, Sheehan AL, Codling BW, Read MD Efficacy and safety of large-loop excision of the transformation zone. Lancet 1994; 343(8888): 32-4.

[141] Alexander KA. Diagnosis and management of human papillomavirus infections. Pediatr Infect Dis J 2005; 24(11): 1007-8.

[142] Sonnex C, Lacey CJ. The treatment of human papillomavirus lesions of the lower genital tract. Best Pract Res 2001; 15(5): 801-16.

[143] Brentjens MH, Yeung-Yue KA, Lee PC, Tyring SK. Human papillomavirus: a review. Dermatol Clin 2002; 20(2): 315-31.

[144] Lacey CJ. Therapy for genital human papillomavirus-related disease. J Clin Virol 2005; 32 Suppl 1: S82-90.

[145] Fox PA, Tung MY. Human papillomavirus: burden of illness and treatment cost considerations. Am J Clin Dermatol 2005; 6(6): 36581

[146] Andrei G, Snoeck R, Schols D, De Clercq E. Induction of apoptosis by cidofovir in human papillomavirus (HPV)-positive cells. Oncol Res 2000; 12(9-10): 397-408.

[147] Snoeck R, Bossens M, Parent D, et al. Phase II double-blind, placebo-controlled study of the safety and efficacy of cidofovir topical gel for the treatment of patients with human papillomavirus infection. Clin Infect Dis 2001; 33(5): 597-602.

[148] Snoeck R, De Clercq E. Role of cidofovir in the treatment of DNA virus infections, other than CMV infections, in immunocompromised patients. Curr Opin Investig Drugs 2002; 3(11): 1561-6.

[149] Orlando G, Fasolo MM, Beretta R, Merli S, Cargnel A. Combined surgery and cidofovir is an effective treatment for genital warts in HIV-infected patients. AIDS (London, England) 2002; 16(3): 44750

[150] Wemer RD, Lee JH, Hoffman HT, Robinson RA, Smith RJ. Case of progressive dysplasia concomitant with intralesional cidofovir administration for recurrent respiratory papillomatosis. Ann Otol Rhinol Laryngol 2005; 114(11): 836-9.

[151] Kimberlin DW. Current status of antiviral therapy for juvenileonset recurrent respiratory papillomatosis. Antiviral Res 2004; 63(3): 141-51.

[152] Edwards L, Ferenczy A, Eron L, et al. Self-administered topical $5 \%$ imiquimod cream for external anogenital warts. HPV Study Group. Human PapillomaVirus. Arch Dermatol 1998; 134(1): 25 30

[153] Menzo S, Marinelli K, Bagnarelli P, Rolla S, Clementi M. Human papillomavirus infections: new perspectives for prevention and treatment. New Microbiol 2007; 30(3): 189-212.

[154] Davis G, Wentworth J, Richard J. Self-administered topical imiquimod treatment of vulvar intraepithelial neoplasia. A report of four cases. J Reprod Med 2000; 45(8): 619-23.

[155] Pehoushek J, Smith KJ. Imiquimod and 5\% fluorouracil therapy for anal and perianal squamous cell carcinoma in situ in an HIV-1positive man. Arch Dermatol 2001; 137(1): 14-6.

[156] Orengo I, Rosen T, Guill CK. Treatment of squamous cell carcinoma in situ of the penis with 5\% imiquimod cream: a case report. J Am Acad Dermatol 2002; 47(4 Suppl): S225-8.

[157] Roberts JN, Kines RC, Katki HA, Lowy DR, Schiller JT. Effect of Pap Smear Collection and carrageenan on cervicovaginal Human Papillomavirus-16 infection in a Rhesus Macaque model. Natl Cancer Inst 2011; 103(9): 737-43

[158] Zhang YQ, Tsai YC, Monie A, Hung CF, Wu TC. Carrageenan as an adjuvant to enhance peptide-based vaccine potency. Vaccine 2010; 28(32): 5212-9.

[159] Wilson VG, Rosas-Acosta G. Molecular targets for papillomavirus therapy. Curr Drug Targets 2003; 3(3): 221-39.

[160] DiPaolo JA, Alvarez-Salas LM. Advances in the development of therapeutic nucleic acids against cervical cancer. Expert Opin Biol Ther 2004; 4(8): 1251-64.

[161] Klingelhutz AJ, Foster SA, McDougall JK. Telomerase activation by the E6 gene product of human papillomavirus type 16. Nature 1996; 380(6569): 79-82. 
[162] Cong YS, Wright WE, Shay JW. Human telomerase and its regulation. Microbiol Mol Biol Rev 2002; 66(3): 407-25, table of contents.

[163] Patel D, Huang SM, Baglia LA, McCance DJ. The E6 protein of human papillomavirus type 16 binds to and inhibits co-activation by CBP and p300. EMBO J 1999; 18(18): 5061-72.

[164] Zimmermann H, Degenkolbe R, Bernard HU, O'Connor MJ. The human papillomavirus type 16 E6 oncoprotein can down-regulate p53 activity by targeting the transcriptional coactivator CBP/p300. J Virol 1999; 73(8): 6209-19.

[165] Massimi P, Banks L. Repression of p53 transcriptional activity by the HPV E7 proteins. Virology 1997; 227(1): 255-9.

[166] Zerfass-Thome K, Zwerschke W, Mannhardt B, Tindle R, Botz JW, Jansen-Durr P. Inactivation of the cdk inhibitor p27KIP1 by the human papillomavirus type 16 E7 oncoprotein. Oncogene 1996; 13(11): 2323-30.

[167] Mantovani F, Banks L. The human papillomavirus E6 protein and its contribution to malignant progression. Oncogene 2001; 20(54): 7874-87.

[168] Ritchie JM, Smith EM, Summersgill KF, et al. Human papillomavirus infection as a prognostic factor in carcinomas of the oral cavity and oropharynx. Int J Cancer 2003; 104(3): 336-44.

[169] Ostwald C, Muller P, Barten M, et al. Human papillomavirus DNA in oral squamous cell carcinomas and normal mucosa. J Oral Pathol Med 1994; 23(5): 220-5.

[170] Watts SL, Brewer EE, Fry TL. Human papillomavirus DNA types in squamous cell carcinomas of the head and neck. Oral Surg Oral Med Oral Pathol 1991; 71(6): 701-7.

[171] Kim SH, Koo BS, Kang S, Park K, Kim H, Lee KR, et al. HPV integration begins in the tonsillar crypt and leads to the alteration of p16, EGFR and c-myc during tumor formation. Int J Cancer 2007; 120(7): 1418-25.

[172] Furrer VE, Benitez MB, Furnes M, Lanfranchi HE, Modesti NM. Biopsy vs. superficial scraping: detection of human papillomavirus $6,11,16$, and 18 in potentially malignant and malignant oral lesions. J Oral Pathol Med 2006; 35(6): 338-44.

[173] Luo CW, Roan CH, Liu CJ. Human papillomaviruses in oral squamous cell carcinoma and pre-cancerous lesions detected by PCR-based gene-chip array. Int J Oral Maxillofac Surg 2007; 36(2): 153-8.

[174] Giovannelli L, Campisi G, Colella G, et al. Brushing of oral mucosa for diagnosis of HPV infection in patients with potentially malignant and malignant oral lesions. Mol Diagn Ther 2006; 10(1): 49-55.

[175] Kellokoski J, Syrjanen S, Yliskoski M, Syrjanen K. Dot blot hybridization in detection of human papillomavirus (HPV) infections in the oral cavity of women with genital HPV infections. Oral Microbiol Immunol 1992 a; 7(1): 19-23.

[176] Saheb-Jamee M, Boorghani M, Ghaffari SR, Atarbashi Moghadam F, Keyhani A. Human papillomavirus in saliva of patients with oral squamous cell carcinoma. Med Oral Patol Oral Cir Bucal 2009; 14(10): e525-8.

[177] Smith EM, Ritchie JM, Summersgill KF, et al. Human papillomavirus in oral exfoliated cells and risk of head and neck cancer. $\mathbf{J}$ Natl Cancer Inst 2004; 96(6): 449-55.

[178] D'Souza G, Sugar E, Ruby W, Gravitt P, Gillison M. Analysis of the effect of DNA purification on detection of human papillomavirus in oral rinse samples by PCR. J Clin Microbiol 2005; 43(11): 5526-35.

[179] Termine N, Panzarella V, Falaschini S, et al. HPV in oral squamous cell carcinoma vs head and neck squamous cell carcinoma biopsies: a meta-analysis (1988-2007). Ann Oncol 2008; 19(10): 1681-90.

[180] Puranen M, Yliskoski M, Saarikoski S, Syrjanen K, Syrjanen S. Vertical transmission of human papillomavirus from infected mothers to their newborn babies and persistence of the virus in childhood. Am J Obstet Gynecol 1996; 174(2): 694-9.

[181] Puranen MH, Yliskoski MH, Saarikoski SV, Syrjanen KJ, Syrjanen SM. Exposure of an infant to cervical human papillomavirus infection of the mother is common. Am J Obstet Gynecol 1997; 176(5): 1039-45.

[182] D'Souza G, Sugar E, Ruby W, Gravitt P, Gillison M. Analysis of the effect of DNA purification on detection of human papillomavirus in oral rinse samples by PCR. J Clin Microbiol 2005; 43(11): 5526-35.
[183] Kay P, Meehan K, Williamson AL. The use of nested polymerase chain reaction and restriction fragment length polymorphism for the detection and typing of mucosal human papillomaviruses in samples containing low copy numbers of viral DNA. J Virol Methods 2002; 105(1): 159-70.

[184] Smith EM, Ritchie JM, Summersgill KF, et al. Age, sexual behavior and human papillomavirus infection in oral cavity and oropharyngeal cancers. Int J Cancer 2004; 108(5): 766-72.

[185] Pannone G, Santoro A, Papagerakis S, Lo Muzio L, De Rosa G, Bufo P. The role of human papillomavirus in the pathogenesis of head \& neck squamous cell carcinoma: an overview. Infect Agents Cancer 2011; 6: 4.

[186] Molina PE, McClain C, Valla D, et al. Molecular pathology and clinical aspects of alcohol-induced tissue injury. Alcohol Clin Exp Res 2002; 26(1): 120-8.

[187] Schwartz SM, Daling JR, Doody DR, et al. Oral cancer risk in relation to sexual history and evidence of human papillomavirus infection. J Natl Cancer Inst 1998; 90(21): 1626-36.

[188] Applebaum KM, Furniss CS, Zeka A, et al. Lack of association of alcohol and tobacco with HPV16-associated head and neck cancer. J Natl Cancer Inst 2007; 99(23): 1801-10.

[189] Termine N, Giovannelli L, Matranga D, et al. Oral human papillomavirus infection in women with cervical HPV infection: new data from an Italian cohort and a metanalysis of the literature. Oral Oncol 2011; 47(4): 244-50.

[190] Termine N, Giovannelli L, Matranga D, et al. Low rate of oral human papillomavirus (HPV) infection in women screened for cervical HPV infection in Southern Italy: A cross-sectional study of 140 immunocompetent subjects. J Med Virol 2009; 81(8): 1438-43.

[191] Gillison ML, Koch WM, Shah KV. Human papillomavirus in head and neck squamous cell carcinoma: are some head and neck cancers a sexually transmitted disease? Curr Opin Oncol 1999; 11(3): 191-9.

[192] Chaturvedi AK, Engels EA, Pfeiffer RM, et al. Human papillomavirus and rising oropharyngeal cancer incidence in the United States. J Clin Oncol 2011; 29(32): 4294-301.

[193] Donnelly RF, McCarron PA, Zawislak AA, Woolfson AD. Design and physicochemical characterisation of a bioadhesive patch for dose-controlled topical delivery of imiquimod. Int J Pharm 2006; 307(2): 318-25.

[194] Vescovi P, Manfredi M, Merigo E, et al. Quantic molecular resonance scalpel and its potential applications in oral surgery. $\mathrm{Br} \mathrm{J}$ Oral Maxillofac Surg 2008; 46(5): 355-7.

[195] Yang SW, Lee YS, Chen TA, Wu CJ, Tsai CN. Human papillomavirus in oral leukoplakia is no prognostic indicator of malignant transformation. Cancer Epidemiol 2009; 33(2): 118-22.

[196] Klozar J, Kratochvil V, Salakova M, et al. HPV status and regional metastasis in the prognosis of oral and oropharyngeal cancer. Eur Arch Otorhinolaryngol 2008; 265(Suppl 1): S75-82.

[197] Kumar B, Cordell KG, Lee JS, et al. Response to therapy and outcomes in oropharyngeal cancer are associated with biomarkers including human papillomavirus, epidermal growth factor receptor, gender, and smoking. Int J Radiat Oncol Biol Phys 2007; 69(2 Suppl): S109-11.

[198] Hoffmann TK, Sonkoly E, Hauser U, et al. Alterations in the p53 pathway and their association with radio- and chemosensitivity in head and neck squamous cell carcinoma. Oral Oncol 2008; 44(12): 1100-9.

[199] Yu GP, Mehta V, Branovan D, et al. Improved survival among patients with base of tongue and tonsil cancer in the United States. Cancer Causes Control 2011; 23(1): 153-64.

[200] Kumar B, Cordell KG, Lee JS, et al. EGFR, p16, HPV Titer, Bcl$\mathrm{xL}$ and $\mathrm{p} 53$, sex, and smoking as indicators of response to therapy and survival in oropharyngeal cancer. J Clin Oncol 2008; 26(19): 3128-37.

[201] Reimers N, Kasper HU, Weissenborn SJ, et al. Combined analysis of HPV-DNA, p16 and EGFR expression to predict prognosis in oropharyngeal cancer. Int J Cancer 2007; 120(8): 1731-8.

[202] Spencer CR, Gay H, Haughey BH, et al. Outcomes in HPVassociated oropharyngeal squamous cell carcinoma after postoperative or definitive nonsurgical therapy. J Clin Oncol 2010; 28(suppl; abstr 5544): 15s.

[203] Attner P. Factors predicting survival outcomes for patients with HPV-positive base of tongue cancer. J Clin Oncol 2011; 29(suppl; abstr 5575). 
[204] Attner P, Du J, Nasman A, et al. Human papillomavirus and survival in patients with base of tongue cancer. Int J Cancer 2011; 128(12): 2892-7.

[205] Arbyn M, Bryant A, Beutels P, et al. Prophylactic vaccination against human papillomaviruses to prevent cervical cancer and its precursors (Protocol). Cochrane Database of Systematic Reviews 2011(4, Art. No.: CD009069, DOI: 10.1002/14651858. CD009069.).

[206] D'Souza G, Dempsey A. The role of HPV in head and neck cancer and review of the HPV vaccine. Prev Med 2011; 53 (Suppl 1): S5S11.

[207] Syrjanen K. Persistent high-risk human papillomavirus (HPV) infections as surrogate endpoints of progressive cervical disease. Potential new endpoint for efficacy studies with new-generation (non-HPV 16/18) prophylactic HPV vaccines. Eur J Gynaecol Oncol 2011; 32(1): 17-33.

[208] CDC. Centers for Disease Control and Prevention. FDA licensure of quadrivalent human papillomavirus vaccine (HPV4, Gardasil) for use in males and guidance from the Advisory Committee on Immunization Practices (ACIP). MMWR 2010; 59: 630-2 http: //www.cdc.gov/mmwr/preview/mmwrhtml/mm5920a5.htm.

[209] Giuliano AR, Lee JH, Fulp W, et al. Incidence and clearance of genital human papillomavirus infection in men (HIM): a cohort study. Lancet 2011; 377(9769): 932-40.

[210] Garland SM, Smith JS. Human papillomavirus vaccines: current status and future prospects. Drugs 2010; 70(9): 1079-98.
[211] Lu B, Kumar A, Castellsague X, Giuliano AR. Efficacy and safety of prophylactic vaccines against cervical HPV infection and diseases among women: a systematic review \& meta-analysis. BMC Infect Dis 2011; 11: 13.

[212] CDC. Centers for Disease Control and Prevention. FDA licensure of bivalent human papillomavirus vaccine (HPV2, Cervarix) for use in females and updated HPV vaccination recommendations from the Advisory Committee on Immunization Practices (ACIP). MMWR 2010; 59: 626-9 Accessed at http //www.cdc.gov/mmwr/preview/mmwrhtml/mm5920a4.htm.). .

[213] WHO. Initiative for Vaccine Research of the Department of Immunization Vaccines and Biologicals. Human Papillomavirus (HPV) Vaccine Background Paper World Health Organization2009. p. 1249.

[214] Bogaards JA, Coupe VM, Xiridou M, Meijer CJ, Wallinga J, Berkhof J. Long-term impact of human papillomavirus vaccination on infection rates, cervical abnormalities, and cancer incidence. Epidemiology (Cambridge, Mass 2011; 22(4): 505-15.

[215] Kim JJ, Goldie SJ. Cost effectiveness analysis of including boys in a human papillomavirus vaccination programme in the United States. BMJ 2009; 339: b3884.

[216] Markowitz LE, Hariri S, Unger ER, Saraiya M, Datta SD, Dunne EF. Post-licensure monitoring of HPV vaccine in the United States. Vaccine 2010; 28(30): 4731-7. 